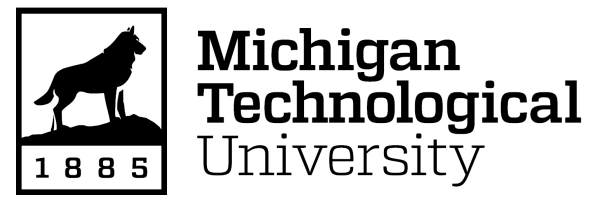

Michigan Technological University Digital Commons @ Michigan Tech

Dissertations, Master's Theses and Master's Reports

2016

\title{
LABORATORY MEASUREMENTS OF CONTACT NUCLEATION BY MINERAL DUSTS, BACTERIA, AND SOLUBLE SALTS
}

Joseph Niehaus

Michigan Technological University, jniehaus@mtu.edu

Copyright 2016 Joseph Niehaus

\section{Recommended Citation}

Niehaus, Joseph, "LABORATORY MEASUREMENTS OF CONTACT NUCLEATION BY MINERAL DUSTS, BACTERIA, AND SOLUBLE SALTS", Open Access Dissertation, Michigan Technological University, 2016.

https://doi.org/10.37099/mtu.dc.etdr/105

Follow this and additional works at: https://digitalcommons.mtu.edu/etdr

Part of the Atmospheric Sciences Commons 


\title{
LABORATORY MEASUREMENTS OF CONTACT NUCLEATION BY MINERAL DUSTS, BACTERIA, AND SOLUBLE SALTS
}

\author{
By \\ Joseph Niehaus
}

\begin{abstract}
A DISSERTATION
Submitted in partial fulfillment of the requirements for the degree of DOCTOR OF PHILOSOPHY

In Atmospheric Sciences
\end{abstract}

MICHIGAN TECHNOLOGICAL UNIVERSITY

2016

(C) 2016 Joseph Niehaus 
This dissertation has been approved in partial fulfillment of the requirements for the Degree of DOCTOR OF PHILOSOPHY in Atmospheric Sciences.

Department of Physics

\author{
Dissertation Advisor: Dr. Will Cantrell \\ Committee Member: Dr. Raymond Shaw \\ Committee Member: Dr. Jennifer Becker \\ Committee Member: Dr. Lynn Mazzoleni \\ Committee Member: Dr. Alexander Kostinski \\ Department Chair: Dr. Ravindra Pandey
}




\section{Dedication}

To my beloved Zoë Coombs,

I apologize for the snow. 


\section{Contents}

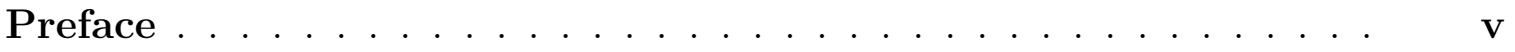

Abstract .......................

1 Introduction . . . . . . . . . . . . . . . . . . . . . 1

1.1 Nucleation Theory . . . . . . . . . . . . . . . . . . 1

1.2 History of Contact Nucleation . . . . . . . . . . . . . 4

2 Articles Concerning Contact Mode . . . . . . . . . . . 8

3 A Technique to Measure Ice Nuclei in the Contact Mode . . . 10

4 Laboratory measurements of contact freezing by dust and bacteria at temperatures of mixed phase clouds . . . . . . . . . 23

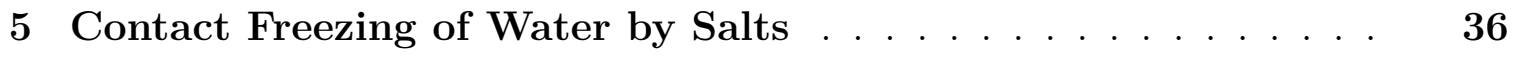

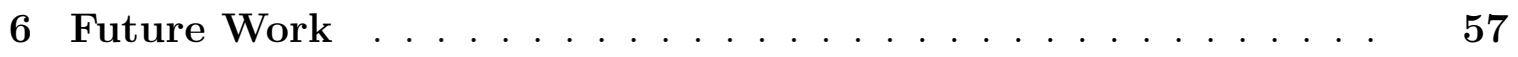

6.1 Terminal Velocity . . . . . . . . . . . . . . . 57

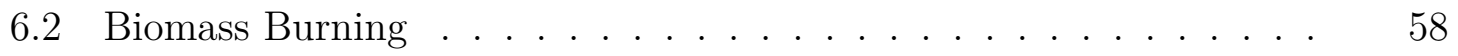

6.2.1 Biomass Generation for the CINC . . . . . . . . . 58

6.2 .2 Preliminary Results . . . . . . . . . . . . . . . 59

References ...................... 61 


\section{Preface}

The experimental apparatus described in the first article, A technique to measure ice nuclei in the contact mode, and used in the second was developed by Kris Bunker and Will Cantrell. The calibration of the collected fraction was a collaborative effort between myself, Kris Bunker, and Swarup China. Swarup and Kris gathered mineral dust samples from the aerosol flow, and analyzed them with a Scanning Electron Microscope. Ashima Chhabra assisted in recording data for the sample P. syringae.

In the second article Laboratory measurements of contact freezing by dust and bacteria at temperatures of mixed phase clouds, samples of mineral dust were provided by Thomas Whale and Benjamin Murray (K-feldspar), and Adam Durant (rhyolitic ash). The bacterial sample of Pseudomonas fluorescens was provided by Nufarm Americas and cultured by Adam Cary, who freeze dried the bacteria for later aerosol use. The experiment and data analysis was performed by myself. Alexander Kostinski provided support in the form of theoretical understanding, and Jennifer Becker collaborated with writing of the article.

The third article, Contact freezing by soluble salts, was an experiment designed by Will Cantrell and myself, and built by our very talented machinist Jesse Nordeng. I was responsible for all the data collection and a majority of analysis, with support from Will. The article was collaboratively written. 


\section{Abstract}

We present results from experiments that emulate atmospheric ice nucleation by aerosols. We have refined experimental techniques to improve measurements of ice forming nuclei in the contact mode. Our results show that atmospherically relevant dusts such as kaolinite, feldspar, rhyolitic ash, and Arizona Test Dust have efficiencies in the contact mode that are higher than the immersion mode. Experiments with bacteria show that biological material has the potential to contribute significantly to ice concentrations, but has large variability. By choosing a soluble compound as an ice nucleus, we are able to place bounds on the timescale for contact freezing and estimate the nucleation time from impact to be $10^{-9}$ seconds. Finally, we conclude that the contact mode can increase nucleation rates in two ways: by the creation of a triple-phase line with an insoluble nucleus, or by the collision event. 


\section{Chapter 1}

\section{Introduction}

\subsection{Nucleation Theory}

Ice nucleation is a phenomenon characterized by the sudden phase transition from metastable liquid water to solid ice. The liquid becomes metastable when cooled past its melting point, and the phase transition of freezing does not occur at $273.15 \mathrm{~K}$ due to the impossibility of suddenly "snapping" every molecule into a crystal lattice. Creating a new surface of the child phase has an energy penalty proportional to the area $A$ of the surface. The constant of proportionality is the surface free energy $(\sigma)$, and the change in Gibbs Free Energy $(G)$ from creating that surface is

$$
\Delta G=A \sigma_{i l}
$$

where $\sigma_{i l}$ denotes the interface of ice and liquid. This is analogous to the surface tension $\sigma_{l v}$, where the interface is between liquid and vapor. The benefit derived 
from partitioning to the more stable phase is the difference in chemical potentials between the ice and liquid, multiplied by the volume of new phase,

$$
\Delta G=-V\left(\mu_{i}-\mu_{l}\right) .
$$

Here $\mu_{i}$ is the chemical potential per unit volume of the ice phase, and $\mu_{l}$ the liquid phase. The change is negative indicating a reduction in the potential of the system. Combining the equations, the Gibbs Free Energy creates a potential well, where the metastable liquid water exists until it is able to overcome the energy barrier due to creation of a surface,

$$
\Delta G=A \sigma_{i l}-V\left(\mu_{i}-\mu_{l}\right)
$$

This describes homogeneous nucleation, where the ice forms spontaneously within the liquid phase. Atmospheric scientists are generally concerned with the rate of formation of the ice phase. This can give information about the evolution of clouds and formation of precipitation. Supposing the geometry of the new phase is spherical, Eq. 1.3 can be written as

$$
\Delta G=4 \pi r^{2} \sigma_{i l}-\frac{4}{3} \pi r^{3}\left(\mu_{i}-\mu_{l}\right),
$$

where $r$ is the radius of the ice embryo. By solving the equation above for its maximum, the critical radius $(r *)$ is found at which any larger embryos will grow without bound as the new solid phase. The population of pre-critical embryos is given by the Boltzmann distribution, 


$$
n(r)=n_{L} \exp \left(\frac{-\Delta G}{k T}\right)
$$

$n_{L}$ is the number density of liquid molecules per unit volume, and $n(r)$ is the number of embryos. The number of nucleation events per unit volume is equal to the number of embryos at the critical size, which gain one more water molecule and begin to grow as each additional molecule is energetically favorable. The rate at which critical embryos gain that additional molecule was derived by Turnbull and Fisher as the jump frequency $(k T / h)$ times the activation energy of a single molecule $\exp (\Delta g / k T)$ [13], yielding

$$
J=\frac{n_{l} k T}{h} \exp \left(\frac{\Delta g}{k T}\right) \exp \left(\frac{-\Delta G^{*}}{k T}\right)
$$

where $J$ is the rate of formation of supercritical clusters per unit volume and $\Delta G^{*}$ is the energy barrier. Although this expression is complete for homogeneous nucleation, determination of $\Delta G^{*}$ has proven difficult.

Ice formation in the atmosphere is found to proceed through either homogeneous or heterogeneous nucleation. For atmospheric conditions, homogeneous nucleation occurs when temperatures are at or below -38ǍžC (Puppacher \& Klett 2010)[18]. Heterogeneous ice nucleation requires the presence of a foreign catalyst and proceeds through four pathways at temperatures higher than the homogeneous limit. Deposition nucleation is the process where water vapor deposits directly onto a solid surface directly in the form of ice. Condensation/immersion nucleation is characterized by the presence of a solid particle in the bulk of the liquid that catalyzes freezing. Contact nucleation is identified by aerosol particles on the surface of supercooled water droplets that initiate freezing. 
The effect of the heterogeneous nuclei is to lower the energy barrier, thus promoting the nucleation rate at higher temperatures. Our focus is on contact mode nucleation, which appears to promote freezing to the highest temperatures. A full treatment of the heterogeneous nucleation rate equation is rather exhaustive, and does not provide much insight or accuracy. Similar to the homogeneous equation, an accurate calculation of the rate rests on a number of thermodynamic terms which are simply not yet well constrained. We choose to focus our work on the contact mode because the other modes have been characterized empirically, whereas contact mode has very little quantitative information available. It also presents an interesting challenge, because the difference between contact and immersion modes is not yet understood mechanistically.

\subsection{History of Contact Nucleation}

The very first laboratory observations of contact mode possibly occurred in the the late 40s, but due to a lack of development in the field were not immediately recognized as a distinct nucleation mode (Rau W. 1949) ${ }^{1}$. It was recognized and delineated later by Gokhale and Goold (1968)[11] when they used experiments to show particles that came into contact with the droplet after it had been supercooled exhibited nucleation at higher temperatures than if the particle is placed on or in the droplet before cooling.

Gokhale and Spengler (1971)[12] expanded this work to a vertical wind tunnel and freely suspended water droplets. Using AgI, some clays, and sand, in the size range of 2-8um, they found contact freezing could be initiated at around -3 to $-9 \mathrm{C}$. However they made little effort to quantify the amount of substance contacting the droplet. Sax and Goldsmith (1972)[19] soon performed similar experiments of supercooled droplets

${ }^{1}$ Unterkhulbarkeit des Wassers und atmosphärische Eisbildung. Wetter und Klima, 2, 81-92 
falling through an aerosol cloud. They used Aitken sized aerosol, and found freezing temperatures from -10 to $-19 \mathrm{C}$ which began to hint that the size or surface area of the particle makes a difference. Pitter and Pruppacher (1973)[17] set up a vertical wind tunnel similar to Gokhale and Spengler (1971) and used it to estimate the relevance of contact mode to the atmosphere by performing a number of experiments that emulated atmospheric conditions.

Ice nucleation, up until this point in history, had been reported in terms of the frozen fraction. This number is the number of water droplets that freeze out of a population when each droplet is exposed to similar conditions. Those conditions could be a pinch of dust sprinkled on droplets, some silver iodide sprayed from a nebulizer, or a small dust sample injected into an air stream. The qualitative conclusions were apparent; contact mode reliably initates freezing at the warmest temperatures. Pitter and Pruppacher (1973) made the first attempt at quantifying aerosol particle number by assuming laminar flow around their droplets and calculating the collision rate of small particles in an airflow around the droplet, coming up with a number of "thousands". By using some atmospherically motivated dusts and a more complete treatment of temperature profiles, they concluded that contact mode has the possibility of being very relevant to atmospheric ice nuclei concentrations.

An exhaustive survey of organic materials was performed by A. Fletcher (1972) [6] that found out of 1000 substances, only 47 qualified as "good ice nuclei". In the mid 70s, the question "What makes contact mode distinct from immersion mode?" had yet to be answered. With classical nucleation theory (CNT) being found in good agreement with pure liquid water droplets, N.H. Fletcher's 1958 work[7] Size Effect in Heterogeneous Nucleation seemed to indicate that a full understanding of heterogeneous modes was only a few unknown, but measurable, variables away. W. Cooper (1974)[2] published a very provoking theory of the contact nucleation mechanism, which was heavily debated by N. Fukuta who then published his own theory in 1975 . 
Both of these are explained in more detail in section 4. They both extend CNT and have testable hypothesis for the requirements of a contact ice nucleus (IN).

After the 1970s, many more researchers took on the challenge of contact nucleation. Biological substances such as bacteria, pollen, and leaf matter were tested. Soil samples were dug up and people gathered clays and dusts from around the world. The findings expanded our knowledge base but only did not make clear the underlying principles of contact mode. Studies of the other modes also expanded, and due to interest from the atmospheric community, immersion mode became the most studied. With numerous field measurement campaigns such as the NASA sponsored ARCTAS2, and Department of Energy sponsored ISDAC3 and M-PACE4, a gap in predictions of ice number concentrations opened up. It was found that immersion and deposition modes had significant trouble explaining ice production in mixed phase arctic clouds[16] 21]. It was proposed that contact mode could help bridge the gap, but more work was necessary to fully characterize the process.

Westbrook and Illingworth[21] have recently completed a survey of the ice production in Arctic stratus clouds, and found that entrainment methods and local cooling are unable to explain the gradual freezing observed. The entrained aerosol population is not enough to replenish depletion of IN by immersion and deposition freezing. They suggest that perhaps the stochastic nature of freezing is continually creating ice particles. Nominally poor ice nuclei have a residence time within droplets long enough to freeze the droplet, causing continual regeneration of the IN count. They also suggest that collection from interstitial aerosol can lead to contact freezing, and that collection is slow enough to gradually turn liquid droplets to ice. Modeling work by Yang et al. (2013) support these hypotheses, showing that the ice particle creation is volumetric, and occurs throughout the cloud instead of just at the top or bottom (as one might expect from entrainment). 
Recent work by Hoffmann et al.[14] has studied the effectiveness of mineral dusts in the contact mode. They employ an electrodynamic balance to levitate water droplets, and size select particles before introducing them to the droplet. They measure the efficiency, defined as the ratio of impacts causing freezing to total number of particledroplet collisions. Their size resolved experiments show that the super-micron sized fraction of aerosol is a more effective ice nucleus than smaller modes.

Assessment of atmospheric ice nuclei is still an ongoing field of research [15]. Laboratory studies show disagreement in ice nuclei counts, which makes ice microphysical models unreliable for weather and climate prediction. The work described here-in advances the field through laboratory studies of the contact mode. 


\section{Chapter 2}

\section{Articles Concerning Contact Mode}

Our initial impetus was to survey the atmosphere and identify possible relevant ice nuclei. Those could then be tested with a newly developed instrument and the contact mode delineated from the immersion and deposition modes. The first two articles do just that, and demonstrate the expected results that contact freezing can occur at higher temperatures than immersion freezing. In the second article, we discover that some ice-negative bacteria Pseudomonas fluorescens can be a more effective nucleator than the mineral dusts kaolinite, rhyolitic ash, and Arizona test dust. Bacteria without IN genes have been ignored as not contributing at all to ice counts in the atmosphere, although we show that they may still be relevant. We also find that a strand of Pseudomonas syringae (CC94) without the usual INA gene has no nucleating efficiency, leading to the conclusion that there is a wide variability in biological substances.

The last article departs from the first two in purpose. The difference between contact and immersion freezing has two leading theories, one proposed by Norihiko Fukuta[10] 
and the other William A. Cooper[2]. Neither had been tested empirically, but provided a number of predictions on the requirements for an ice nucleus that could be investigated. Our experiments led to the discovery of ice nucleation by exothermic salts, and possibly a new mechanism of contact freezing. By ruling out all other possibilities, we find that only the impact is able to trigger freezing. Knowing this, we are able to place a bound on the timescale for the critical embryo to form, and find it to be before the heat of dissolution raises the temperature of the supercooled droplet. 


\section{Chapter 3}

\section{A Technique to Measure Ice Nuclei in the Contact Mode}

The material contained in this chapter was previously published in Journal of Oceanic and Atmospheric Technology. The work is copyrighted by the American Meteorological Society and is reprinted with permission. 


\title{
A Technique to Measure Ice Nuclei in the Contact Mode
}

\author{
Joseph Niehaus, Kristopher W. Bunker, Swarup China \\ Alexander Kostinski, Claudio Mazzoleni, and Will Cantrell * \\ Michigan Technological University, Houghton, Michigan
}

\begin{abstract}
We present a new technique to study ice nucleation by aerosols in the contact mode. Contact freezing depends upon the interaction of a supercooled droplet of water and an aerosol particle, with the caveat that the particle must be at the air-water interface. To measure nucleation catalyzed in this mode, we employ water droplets which are supercooled via a temperature controlled copper stage, then pull aerosol laden air past them. Particles deposit out of the air stream and come into contact with the surface of the droplet. We report the probability that a particle-droplet collision initiates a freezing event, necessitating knowledge of the total number of particles which collide with the droplet. In tests of the technique, we find that ice nucleation by the bacteria Pseudomonas syringae is more efficient in the contact mode than in the immersion mode by two orders of magnitude at $-3{ }^{\circ} \mathrm{C}$ with the difference diminishing by $-8^{\circ} \mathrm{C}$.
\end{abstract}

\section{Introduction}

Atmospheric aerosol may catalyze formation of ice in Earth's atmosphere through four known nucleation pathways or modes - deposition, immersion, condensation, or contact. In deposition mode nucleation, water vapor adsorbs to the aerosol particle and forms ice directly, without an intervening liquid stage. Immersion and condensation mode nucleation both require the presence of the bulk, supercooled liquid; the difference between the two is primarily in how the particle comes to be surrounded by the liquid phase. In contrast to the first three, contact mode nucleation is initiated by a supercooled droplet of water coming into contact with an aerosol particle. It is the presence of the particle at the air-water interface which triggers the freezing event.

The deposition, immersion, and condensation modes may be quantified by exposing aerosol particles to the appropriate combinations of relative humidity and temperature. For example, deposition nuclei (i.e. those aerosol particles which are active as ice nuclei in the deposition mode at a given temperature) can be detected and counted by exposing aerosol particles to a known temperature and relative humidity with respect to ice. Ice crystals are then the result of deposition nucleation, since the probability of homogeneous nucleation of ice directly from the vapor phase is vanishingly small. The immersion and condensation modes can be quantified by first exposing the aerosol to a supersaturation with respect to water, then exposing the subsequent droplet to a low temperature and monitoring its phase.

Numerous methods have been employed over the past 50 years to accomplish such processing, including filter samples (see e.g. Roberts and Hallett (1968); Bundke et al. (2008)), mixing chambers (e.g. López and Ávila (2013)), and parallel plate diffusion chambers (e.g. Rogers (1988); Hussain and Saunders (1984); Tomlinson and Fukuta (1985)). The key element in all of the instruments is that an aerosol particle's ice nucleation activity is indicated by the presence or absence of ice crystals after all of the particles have been exposed to some combination of temperature and relative humidity. 
Measurements of contact nucleation, unlike deposition and immersion/condensation, cannot be done only by exposing the aerosol to combinations of relative humidity and temperature because aerosol particles must be at the supercooled water droplet's surface. Liquid water and aerosol interactions must be quantified as well as any subsequent freezing event. Initial observations of the phenomenon were carried out by sprinkling powders onto supercooled droplets which were supported on a substrate (Gokhale and Goold, Jr. 1968), or by placing the powder next to the droplet and gently nudging the powder until it made contact (Fletcher 1972). Since then, techniques to measure contact nucleation have included cold plates (Fornea et al. 2009; Shaw et al. 2005), droplets suspended in electrodynamic traps and wind tunnels (Hoffmann et al. 2013; Svensson et al. 2009; Pitter and Pruppacher 1973), and flow through cloud chambers (Ladino et al. 2011). (For a more comprehensive review of the techniques and instruments which have been used to measure contact nucleation, see Ladino et al. (2013).)

In some configurations (e.g. those used by Fletcher (1972), Shaw et al. (2005), and Fornea et al. (2009)), cold plates have the advantage of minimizing the uncertainty in the number of particle-droplet contacts which have occurred, because the contact between nucleating agent and supercooled droplet is physically observed. For heterogeneous ice nucleation, the main catalyst of freezing is particle-droplet interactions, and these instruments provide for very controlled environments. The disadvantage in those cases is that the contact area between particle(s) and droplet is relatively large, far greater than the typical aerosol particle-droplet interaction in the atmosphere. Hence collision rates and number of collected particles may not be indicative of atmospheric conditions. This condition could, however, be a boon in that much larger number concentrations can be probed to provide information about the nucleation process itself. Cold plates are also typically restricted to temperatures greater than about $-25{ }^{\circ} \mathrm{C}$ because larger droplets, which have a large contact area with the supporting substrate, usually freeze for $T<-25^{\circ} \mathrm{C}$ simply because of the contact with the substrate. (Larger droplets do not bias the contact nucleation itself, as the radius of curvature, which is the primary difference between droplets and bulk water, of even $10 \mu \mathrm{m}$ diameter droplets is large enough to have little effect on the molecular scale interaction between the aerosol particle and the droplet.) The final restriction is that cold plates are usually more labor intensive since droplets must be replaced once they are frozen.

Electrodynamic traps (Hoffmann et al. 2013; Svensson et al. 2009), wind tunnels (Pitter and Pruppacher 1973), and flow through cloud chambers (Ladino et al. 2011) can access much lower temperatures (the homogeneous nucleation limit) because the droplet is suspended in air. Such systems can usually process a larger number of droplets, which improves the statistics in terms of the number of freezing events observed. However, an increase in the number of observed freezing events usually comes at the expense of fewer aerosol-droplet interactions. The systems are also limited to lower temperatures because of the range of droplet sizes which can be levitated; for higher temperatures smaller droplets evaporate quickly and collide with no (or not enough) particles. Determination of the number of aerosol particle-droplet interactions is also more difficult in such systems (Svensson et al. 2009; Ladino et al. 2011). Hoffmann et al. (2013) address this issue both by a calculation and an empirical measure of particles in the droplet via Scanning Electron Microscope. They calibrate their system and equation for known flow velocity, aerosol size, droplet charge, and aerosol volume flow. Our approach is similar in that it is specific to the constraints of our instrument design but we require no flow calculations of aerosols in air.

We have developed a technique to measure the efficiency with which aerosol particles catalyze freezing in the contact mode for temperatures greater than $\sim-24{ }^{\circ} \mathrm{C}$, where contact freezing is expected to be the dominant mechanism of freezing for non-biological particles. We employ test droplets supported on a cold stage with the aerosol sample in the air stream which is pulled past the test droplet. Our system combines features of the approaches outlined above which al- 
lows us to expose test droplets to aerosol particles of atmospherically relevant sizes and to reliably estimate the number of particles which are deposited to the test droplet before a freezing event.

\section{Overview}

The goal of the experiment is to measure the nucleating efficiency of a sample aerosol in the contact mode as a function of temperature. We define the efficiency as

$$
E=\frac{F}{N_{d}},
$$

where $F$ is the total number of freezing events and $N_{d}$ is the sum of particles on or in the droplets. (We assume that aerosol particles do not bounce off the liquid water surface.) $E$ can be interpreted as answering the question, "What fraction of the aerosol particles which come into contact with the surface of the droplet result in a freezing event?" An efficiency of $10^{-3}$ means that 1000 particles were deposited to the surface of the droplet before freezing occurred.

In our experiments, to measure the nucleating efficiency, a water droplet is cooled to the desired temperature and exposed to a flow of aerosol until it either freezes or the testing time has expired. The maximum length of the tests is taken so that the droplets' size and shape are not significantly altered by evaporation. The system was flushed with dry, filtered air to eliminate the possibility of contamination in each test before aerosol was introduced to the system.

The experiment consists of four major components. In procedural order, they are aerosol generation, conditioning of the air and aerosol stream, monitoring of the phase of the test droplet, and counting the aerosol particles which exit the nucleation chamber. A schematic of the design is shown in Fig. 1. For our laboratory tests, air enters the system from a dry HEPA filtered source into the aerosol generator. The sample stream is then processed through temperature conditioning. The flow passes through

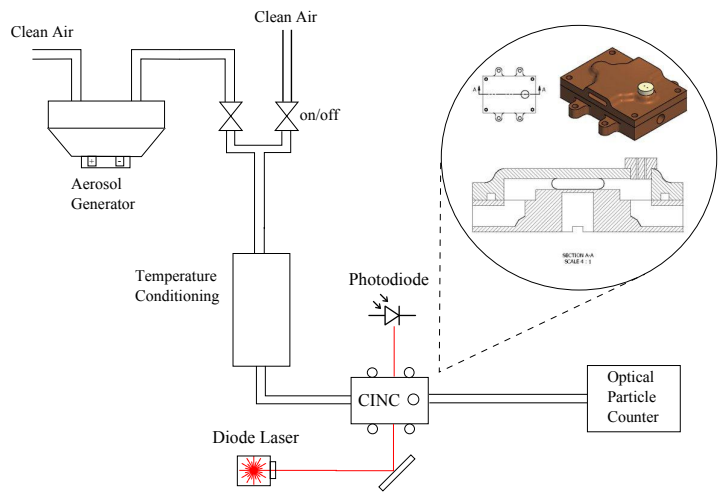

FIG. 1. Schematic of the experimental design. The Contact Ice Nucleation Chamber is shown in the inset. A more detailed cross section is shown in Fig. 2.

the ice nucleation chamber, and lastly exits through an aerosol particle counter. The two valves before the air conditioner allow for easy switching between clean air and aerosol. A water droplet inside the Contact Ice Nucleation Chamber (CINC) sits in the path of the air flow; a small fraction of the aerosol particles in the flow are deposited to it. Upon freezing, light from a laser focused through the droplet scatters, and the corresponding drop in signal from the photodiode is observed. Linear polarizers may also be placed in the path of the beam with one before and one after the CINC to allow phase monitoring via re-polarization of the laser beam. Water does not polarize light and thus polarizers set $90^{\circ}$ from each other will completely block the beam while ice will repolarize the light and the photodiode will register a signal. This system allows us to monitor the phase of a water droplet in the presence of aerosol flow. The number of particle-droplet interactions is calculated by the two methods described in Section 4.

\section{Ice Nucleation Stage}

The heart of the technique is the Contact Ice Nucleation Chamber (CINC), which is designed to support the test droplet at a specified tem- 


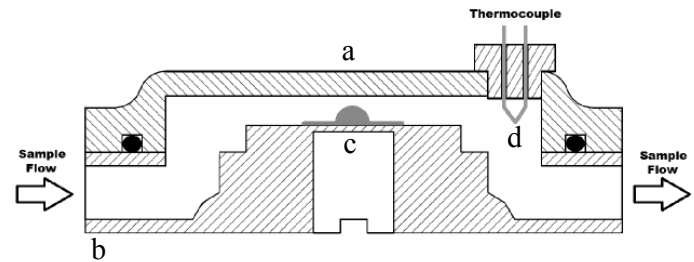

Fig. 2. Cross-section of the Contact Ice Nucleation Chamber (CINC) with letters denoting points where temperature is measured. Platinum Resistance Temperature Devices (RTDs) are used at points a, b, and c. A K-type thermocouple is used at point $d$. The path of the diode laser beam is into the page.

perature and allow monitoring of the phase of the droplet as the stream of test aerosol flows past it. The CINC is a milled copper stage; a cross section is shown in Fig. 2. Windows cut through the side of the top plate allow monitoring of the phase of the $5 \pm 0.1 \mu \mathrm{l}$ test droplet, which sits on a silanized glass slide (Hampton Research, HR3-231) placed on the center stage of the bottom piece.

Freezing events in the chamber are detected by focusing a $1 \mathrm{~mW}, 650 \mathrm{~nm}$ diode laser through the droplet to a photodiode on the other side. When a freezing event occurs, the beam is scattered and the photodiode voltage drops to zero. For higher temperatures, the ice that forms is clearer and only a minor dip in signal is observed. After every test, the top is removed and the droplet is physically inspected, resulting in zero uncertainty for $F$, the number of freezing events. When in situ immersion control tests were performed, the top was not removed and instead the freezing event was confirmed by a very distinct signal drop in the photodiode and accompanying temperature change in the thermocouple downwind of the droplet.

The other relevant parameter in the determination of $E$ is the number of particles that deposit to the droplet, which is, in turn, determined by the characteristics of air flow in the chamber.
The volumetric flow rate for our experiments is chosen to be $1 \mathrm{lpm}$, giving a linear flow velocity of about $0.7 \mathrm{~m} / \mathrm{s}$ at the $\frac{1}{4}^{\prime \prime}$ inlet to the chamber. The Reynolds number for the flow of air past the hemispherical water droplet is approximately 200, which indicates that the flow is in an intermediate regime between turbulent and laminar. The flow in the chamber precludes a simple calculation of the number of particles deposited to the test droplet; we use an empirical method instead, described in section 4 .

Aerosol particles which exit the CINC are counted with an Optical Particle Sizer (OPS, TSI model 3330). It measures the number and size of particles by collimating the flow and recording light scattered by each particle. With dead time corrections, the OPS is accurate to approximately $\pm 10 \%$ of the total number. Alternatively, a TSI Condensation Particle Counter (model 3772) is available. It provides a more accurate reading for number concentrations, but contains no information about size of the particles.

Finally, the temperature of a test droplet in the CINC can be selected by an Accuthermo FTC100D TEC temperature controller coupled with a $12.25 \mathrm{~cm}^{2}$ square Ferrotec thermoelectric Peltier element. The controller and Peltier element have a heat pumping capability of 30 $\mathrm{W}$, enough to cool the chamber at a rate of $\sim 5{ }^{\circ} \mathrm{C}$ per minute. The hot side of the element is cooled by a copper heatsink through which ethylene glycol circulates. The coolant is pumped by a Julabo CF40 Cryo-Compact Circulator; the temperature of the coolant is set to $-20{ }^{\circ} \mathrm{C}$. Temperatures of 30 to $-30{ }^{\circ} \mathrm{C}$ are possible, though the practical, lower limit of the chamber is $-23.5 \pm 0.2{ }^{\circ} \mathrm{C}$, which is set by the heterogeneous freezing limit of test droplets on the glass slides.

The temperature sensor for the FTC100D TEC's control loop is a thin film, 3-wire $100 \Omega$ platinum RTD (Minco); it is located in the recess indicated as point $\mathrm{c}$ in Fig. 2. Two 4wire RTDs of the same type monitor temperatures at points a and b. A K-type thermocouple (Omega) $\frac{1}{16}$ "thick protrudes into the air stream 
at point $\mathrm{d}$.

As noted above, the temperature of the test droplet is not controlled directly. The RTD in the Accuthermo's control loop is approximately $0.5 \mathrm{~mm}$ below the droplet. The thickness of the copper stage is $0.5 \mathrm{~mm}$ at that point, and the glass slides are $\sim 0.03 \mathrm{~mm}$ thick. To determine the temperature of a test droplet for a given setting of the temperature controller, we calibrated the stage using the melting point of the four substances summarized in Table 1. Droplets of the alkanes or water on the CINC stage were cooled until they froze. The frozen droplets were then warmed slowly until melting was observed with a CCD camera. A modified chamber top with a window allowed for a clear view of the stage and samples. Close to the melting point, the temperature, as read by the RTD at point c, was increased by $0.1{ }^{\circ} \mathrm{C}$ steps. The droplet was observed at the new temperature for at least 300 seconds, adequate time for the latent heat of melting to be transferred to the sample. If melting was not observed, the temperature was increased by another $0.1{ }^{\circ} \mathrm{C}$ and the procedure repeated. The readings of the RTD at point $\mathrm{c}$ when the sample droplet melted are shown in the final column of Table 1. Melting was never observed at a temperature lower than what is indicated in the table. In other words, a droplet of pure water does not melt on the stage in the CINC for a temperature reading of $272.2 \mathrm{~K}$, but melts within 30 seconds once the temperature at point $\mathrm{c}$ is increased to $272.3 \mathrm{~K}$. Results shown in Table 1 are from tests conducted in still air. Selected tests were repeated with air flowing through the system, and no change in $T_{m}$ was observed. This is expected because the heat flux is dominated by contributions from the bottom plate; heat flux from air is negligible.

Figure 3 is a plot of the RTD reading at point $\mathrm{c}$ in the chamber as a function of the melting point of the substance on the CINC stage. We interpolate to other temperatures using a linear regression, also shown in Figure 3. Combining the results from Table 1 and the residuals of the fit shown in Fig. 3, we conclude that the uncertainty in the temperature of a test droplet on the CINC stage is $\pm 0.2^{\circ} \mathrm{C}$.

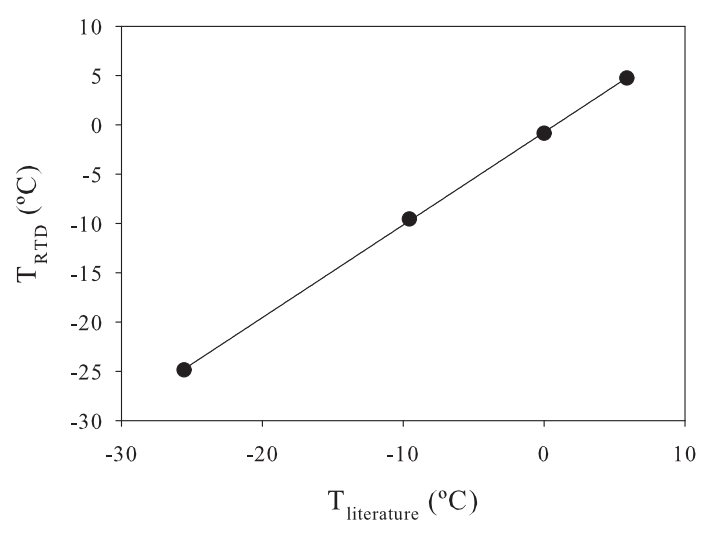

FIG. 3. Reading of the RTD located at point $\mathrm{c}$ in the CINC (see Fig. 2) as a function of the melting point temperature of selected alkanes and water. The linear regression used to determine other temperatures is shown.

\section{Determining the Number of Aerosol Droplet Interactions}

Controlled studies of contact mode nucleation are difficult because the aerosol particles which trigger freezing are commonly too small to be observed or tracked. Our approach is to obtain a statistical measure for the number of particles that deposit to the droplet. We present this

TABle 1. Substances used to calibrate the temperature of a droplet on the CINC stage. The measured temperatures are those from the RTD at point $\mathrm{c}$ in Fig. 2, while the melting point values of the decanes are taken from Finke et al. (1954).

\begin{tabular}{ccc} 
Sample & $\begin{array}{c}\text { Melting } \\
\text { Point }\left({ }^{\circ} \mathrm{C}\right)\end{array}$ & $\begin{array}{c}\text { Temperature } \\
\text { at point c }\end{array}$ \\
\hline n-undecane & -25.56 & -24.85 \\
n-dodecane & -9.56 & -9.55 \\
pure water & 0 & -0.85 \\
n-tetradecane & 5.88 & 4.75 \\
\hline
\end{tabular}


number as the collected fraction,

$$
C F=\frac{N_{d}}{N_{C}},
$$

where $N_{d}$ is the number of aerosol particles that have been deposited to the droplet's surface and $N_{C}$ is the number of particles counted by the particle counter at the exit to the CINC (see Fig. 1). It should be noted that the $C F$ is constant with respect to time and directly measures the ratio of surviving particles counted by the OPS and those found inside the droplet. Hence deposition of aerosol particles to other parts of the chamber or air lines are accounted for. The uncertainties derived include variations in droplet placement, air densities, particle sizes, and flow geometries. The $C F$ is strictly a statistical measure of our deposition rate of aerosol particles in terms of the number counted at the end of the system.

$N_{d}$ is the quantity of interest, as it appears in the denominator of Equation 1. It is not feasible to count particles inside every test droplet after every nucleation test; instead we determine $C F$ in separate experiments, described below, then measure $N_{C}$ and use Equation 2 to find the number of particles deposited to a droplet in a particular test. The value of $C F$ that we use is for flow conditions in the CINC at $1 \mathrm{lpm}$, and these conditions are never altered during subsequent experiments.

\section{a. Method 1}

Kaolinite particles were size selected with a differential mobility analyzer (DAM, TSI 3081) and pulled past water droplets in the CINC; to facilitate analysis with a Scanning Electron Microscope (SEM), test droplets were placed on carbon tape on a glass slide. The number of aerosol particles exiting the chamber was counted with the condensation particle counter (TSI, model 3772). The air flow was then turned off, the droplets allowed to evaporate, and the carbon tape transferred to an $\mathrm{Al}$ stub for analysis.

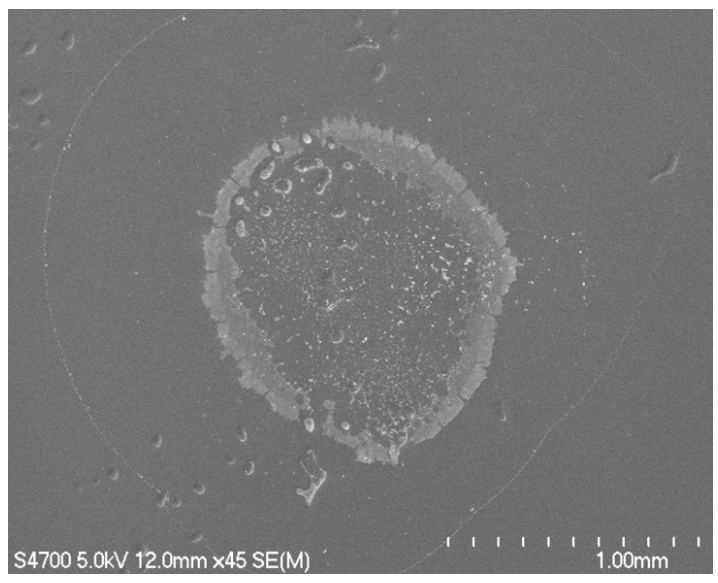

FIG. 4. Residue of kaolinite particles after a test droplet in the CINC evaporates.

The residue shown in Fig. 4 was imaged using an SEM. Individual particle counts cannot be readily determined because particles agglomerate during evaporation and become indistinguishable from each other (see e.g. Fig. 5).

Instead, the number of particles which collided with the test droplet, $N_{d, 1}$, is estimated as

$$
N_{d, 1}=\frac{A_{r}}{\overline{A_{p}}}
$$

where $A_{r}$ is the total surface area of the residue obscured by dust and $\bar{A}_{p}$ is the average crosssectional size of a particle for the size selected by the DMA. The cross sectional area was determined in separate experiments by, for example, selecting a mobility diameter of $500 \mathrm{~nm}$ and examining many single particle cross sections on the filter substrate with the SEM. The mean area of a single particle was found to be $1.1 \pm 0.1 \mu \mathrm{m}^{2}$ and $1.9 \pm 0.2 \mu \mathrm{m}^{2}$ for $1 \mu \mathrm{m}$ and $0.5 \mu \mathrm{m}$ mobility diameter size selections, respectively. ${ }^{1}$

\footnotetext{
${ }^{1}$ The apparent reversal in the average surface areas for the 0.5 and $1 \mu \mathrm{m}$ diameter particles stems from the fact that the DMA selects the particles' mobility diameter, which is inherently three dimensional since it relies on a drag force balancing the electric force exerted on the charged particle. The DMA is selecting the correct mobility, verified with polystyrene latex spheres. However, kaolinite isn't spherical - it is flaky. The area we see in an SEM image is consistent with a $1 \mu \mathrm{m}$ diame-
} 


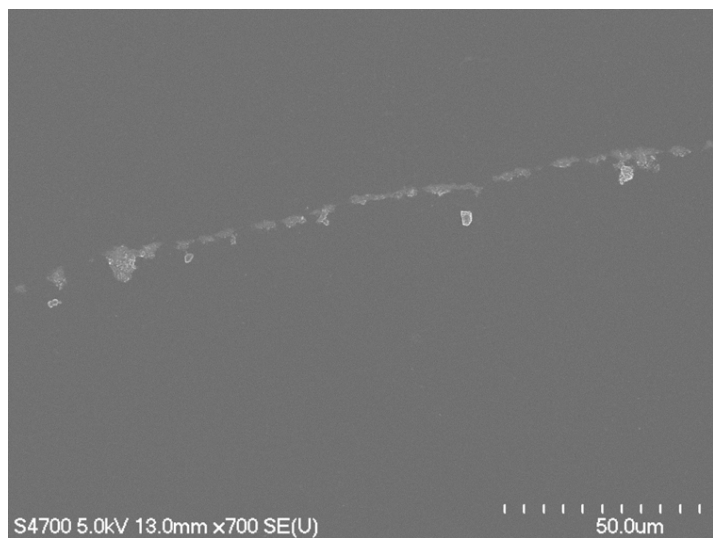

FIG. 5. Edge of the residue which shows a couple of obvious individual particles; most of the rest of the edge is particles which have agglomerated as the droplet evaporated.

Results are shown in Table 2. The uncertainty in the number of particles deposited to the droplet is derived from the uncertainty in the projected area of one particle, stated above, and the uncertainty in $A_{r}$, the total projected area of the dust in the residue of the evaporated droplet, which we conservatively estimate is $25 \%$. The estimation comes from uncertainties in determining surface area of irregularly shaped particles. As the residue evaporates the kaolinite will agglomerate, fusing into larger masses making single particle identification difficult. Futhermore, medium resolution images were required to capture pictures of the entire residue in a timely fashion. The uncertainty is derived from difficulties in distinguishing between single particles and the challenge of strictly bounding particle residues from SEM images.

ter, but the thickness is only a hundred $\mathrm{nm}$ or so. We have verified this in a couple of cases using a tilted SEM stage. (The $500 \mathrm{~nm}$ particles seem to be flakier than the $1 \mu \mathrm{m}$.) We are pursuing this issue further by analyzing the dust using an atomic force microscope, which gives us the three dimensional image of the particles, not just their 2D projection. That, however, is beyond the scope of this paper. b. Method 2

As a check on the collected fractions just described, we used spherical glass beads $5.4 \mu \mathrm{m}$ in diameter (Thermo Scientific, Duke Standards 9000 Series) instead of size selected dust. Even though the glass beads also clump together as the droplet evaporates, their uniform size and shape enables an accurate count of the individual particles within the residue of an evaporated droplet, using a 1000x optical microscope. The results are summarized in Table 3.

\section{c. Comparison of the Methods}

Comparison of the data in Tables 2 and 3 show that, for our experimental setup, the collected fraction is not a strong function of the size of the aerosol particle for particles larger than one micrometer in diameter, as the kaolinite and glass beads were deposited to the test droplets with the same efficiency and almost the same variability. For every thousand particles in the size range one to five microns that go through the CINC (i.e. are counted by the OPS), between three and nine particles are deposited to the droplet, with a mean of six.

The uncertainty in the efficiency of contact ice nuclei in our experiments is dominated by the intrinsic variability in the number of particles which collide with the test droplet for any given experiment. The uncertainty in $E$ is given by

$$
\sigma_{E}=\frac{F}{N_{d}^{2}} \sqrt{\sigma_{N_{C}}^{2} C F^{2}+\sigma_{C F}^{2} N_{C}^{2}}
$$

which shows that the uncertainty is inversely proportional to the square of the number of particles deposited to the droplet. The variation in the collected fraction is the principal contributor to the total uncertainty. 
TABLE 2. Data from tests used to determine the collected fraction of kaolinite. $D_{m}$ is the selected mobility diameter, $\overline{A_{1 \text { particle }}}$ is the average projected area of a single particle of the size selected dust, $N_{d, 1}$ is the number of particles deposited to the test droplet, and $N_{C}$ is the number of particles counted by the condensation particle counter.

\begin{tabular}{cccccc}
$D_{m}(\mu \mathrm{m})$ & Test \# & $\overline{A_{1 \text { particle }}}\left(\mu \mathrm{m}^{2}\right)$ & $N_{d, 1}$ & $N_{C}$ & $\mathrm{CF}$ \\
\hline 1.0 & 1 & $1.1 \pm 0.1$ & $4000 \pm 1000$ & 566125 & $7 \times 10^{-3} \pm 2 \times 10^{-3}$ \\
& 2 & & $2000 \pm 500$ & 357203 & $6 \times 10^{-3} \pm 2 \times 10^{-3}$ \\
0.5 & 1 & $1.9 \pm 0.2$ & $1700 \pm 500$ & 2141805 & $8 \times 10^{-4} \pm 2 \times 10^{-4}$ \\
& 2 & & $700 \pm 200$ & 477059 & $16 \times 10^{-4} \pm 2 \times 10^{-4}$ \\
\hline
\end{tabular}

\section{Measurements}

TABLE 3. Results of tests to determine the collected fraction, $C F$, using glass beads of $5.4 \mu \mathrm{m}$ in diameter. $N_{C}$ is the number of beads counted by the OPS at the exit to the CINC (see Fig. 1) while $N_{d, 2}$ is the number of glass beads counted within the residue of the evaporated test droplet. The mean collected fraction is $0.006 \pm 0.003$.

\begin{tabular}{ccc}
$N_{C}$ & $N_{d, 2}$ & $\mathrm{CF}$ \\
\hline 4054 & 34 & 0.0084 \\
4324 & 24 & 0.0056 \\
5125 & 8 & 0.0016 \\
5869 & 29 & 0.0049 \\
6239 & 45 & 0.0072 \\
7867 & 35 & 0.0044 \\
8605 & 94 & 0.0109 \\
8801 & 46 & 0.0052 \\
9454 & 37 & 0.0039 \\
9960 & 74 & 0.0074 \\
\hline
\end{tabular}

Nucleation tests were performed with the bacteria Pseudomonas syringae, which has a well characterized immersion mode freezing behavior (see e.g. Maki et al. (1974)). The dust sample was generated by grinding pellets of Sno$\max$ (Snomax International), which is a dried form of the bacteria, then dispersing the resulting powder with a custom built vibrating membrane dust dispersal system (see the Appendix). A representative size distribution of the aerosol, taken just after the sample stream has exited the CINC, is shown in Fig. 6. We note that for tests run at $T>-5.0^{\circ} \mathrm{C}$, crossed polarizers were used to detect the onset of ice formation due to the more transparent nature of the solid formed.

The contact freezing efficiency of the aerosolized Snomax, defined by Eq. 1, is plotted as a function of temperature in Fig. 7. For the tests reported here, we use $C F=5 \times 10^{-3} \pm 3 \times 10^{-3}$, which is the mean of the collected fractions reported in sections a and $\mathrm{b}$ above. The uncertainty is the standard error of the mean. Like the immersion mode, the efficiency is low for the higher temperatures and has an asymptotic approach to $10^{-1}$ at $-8{ }^{\circ} \mathrm{C}$. No freezing events were observed for temperatures greater than -3 ${ }^{\circ} \mathrm{C}$; based on our experiments, the efficiency of Snomax in the contact mode is less than $10^{-6}$ for $T>-3{ }^{\circ} \mathrm{C}$.

The asymptotic approach to $E=10^{-1}$ instead of 1 is a bit puzzling at first. How- 


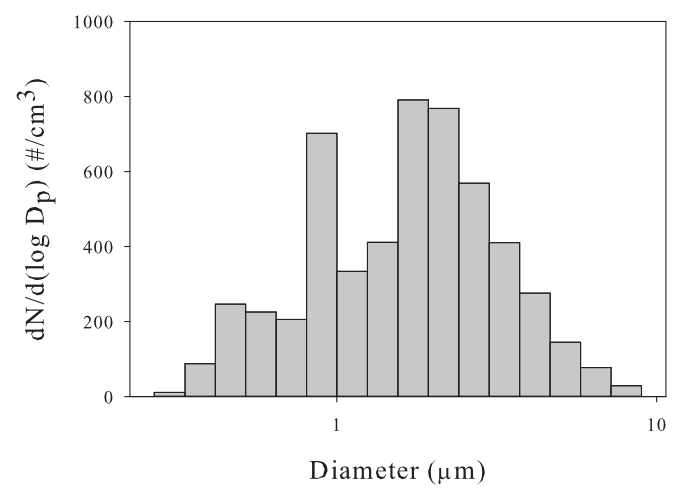

Fig. 6. Averaged size distribution of Snomax measured by the OPS, immediately after the CINC. Uncertainties are given by the manufacturer (TSI) of $10 \%$ of the number concentration in any size bin.

ever, there is evidence suggesting that not every Pseudomonas syringae cell expresses the protein which catalyzes formation of ice at high temperatures. A recent study of ice nucleation of Snomax in the immersion mode showed that even at $-30{ }^{\circ} \mathrm{C}$, only 20 to $30 \%$ of droplets containing a 650 or $800 \mathrm{~nm}$ Snomax particle froze (Hartmann et al. 2013), which is consistent with our results.

One benefit of using bacteria is the number of cells can be calculated from the size of the particles. Pseudomonas syringae cells are rod shaped and have a known size of $\sim 2.0 \mu \mathrm{m}$ long and $1 \mu m$ in diameter (Monier and Lindow 2003). From the size information measured by the OPS, we can calculate the number of cells that collide with the droplet and compare this directly with immersion mode freezing.

\section{Distinguishing Contact Mode}

Inevitably, particles that deposit to the water surface end up in the interior of the droplet and may contribute to immersion mode freezing. Air flow over the surface of the test droplet causes circulation eddies which will pull particles inside

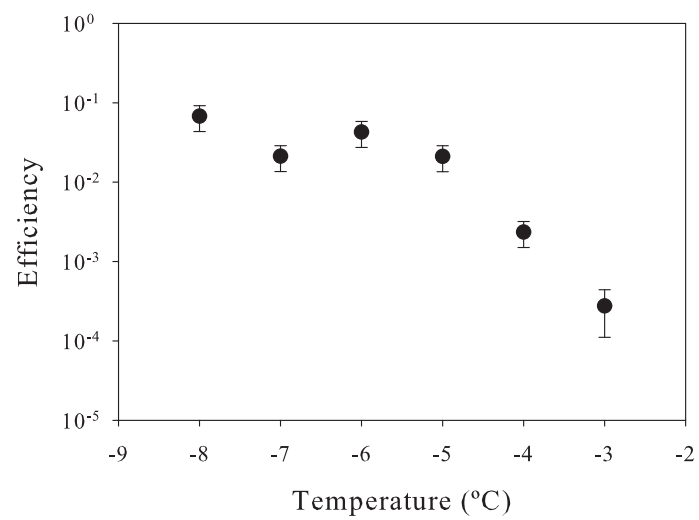

FIG. 7. Efficiency of Snomax particles measured by the CINC.

and mix them. To distinguish our contact freezing events from those that may have been caused from particles inside the droplet, two measures were taken.

First, many droplets which presumably froze in the contact mode were warmed to $10{ }^{\circ} \mathrm{C}$. They were then cooled back to the same temperature at which the test was performed and held steady with clean air flow for 30 minutes. No freezing events occurred. Furthermore, it was found that the droplets which froze at $-3{ }^{\circ} \mathrm{C}$ from Snomax could be supercooled below $-8{ }^{\circ} \mathrm{C}$ before they would spontaneously freeze.

Using diameters reported by the OPS, the number of bacterial cells in an aerosol particle can be calculated. For this analysis, particles smaller than $1 \mu \mathrm{m}$ were ignored because they are most likely nutrient media from the sample preparation. Particles from the sizes $1 \mu m$ to $2.5 \mu m$ were taken to have only one cell, and larger particles had the equivalent spherical volume divided by the volume of a bacterial cell to determine the number of cells. The results were plotted along with immersion mode data from Maki et al. (1974) in Fig. 8. Maki et al. (1974) executed a series of immersion ice nucleation tests on a cultured form of $P$. syringae strain C-9. They did so by preparing a series of droplet freezing assays and measured the number of droplets frozen 


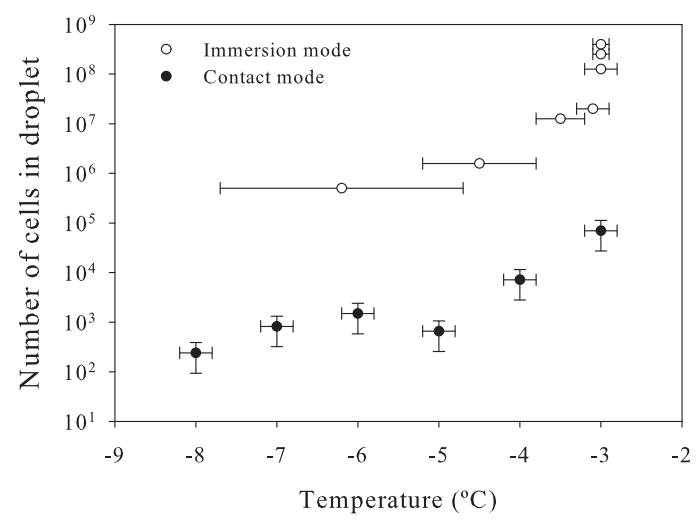

FIG. 8. Open circles are immersion freezing tests adapted from Maki et al. (1974) and filled circles are contact freezing tests from above. Maki et al. report $\mathrm{T}_{50}$, the temperature at which $50 \%$ of the droplets in their freezing assay turned to ice. The bounds on their data are the temperatures at which the droplets started freezing (onset $\mathrm{T}$ ) and $\mathrm{T}_{99}$, the temperature at which $99 \%$ of their droplets frozen. Contact mode for Snomax appears to be more active for all temperatures, but both modes are expected to converge for colder temperatures.

and the temperature. The data represents the temperature at which $50 \%$ of the droplets froze, and the temperature range is given between the onset temperature and $\mathrm{T}_{99}$, where $99 \%$ of the droplets froze. The plot shows that from our tests, contact mode of Snomax is significantly more effective than immersion mode for all temperatures measured. This difference diminishes as the temperature decreases. Through these two pieces of evidence we conclude that none of the freezing events which we observed in our experiments were due to immersion nucleation.

\section{Concluding Remarks}

We have developed a technique to measure the efficiency with which aerosol particles catalyze freezing in the contact mode for temperatures greater than $\sim-24{ }^{\circ} \mathrm{C}$, a range that is relevant for tropospheric, mixed-phase clouds.
Measurement of contact freezing requires that aerosol particles come into contact with the surface of supercooled droplets of water, and that the resulting freezing event (if there is one) be detected. We accomplish that by using test droplets supported on a cold stage; aerosol particles deposit to the droplet from the air stream flowing through our Contact Ice Nucleation Chamber (CINC). We monitor the phase of the test droplet with a diode laser and photodiode, and determine the number of particles which have hit the droplet by examining the evaporated residue of test droplets in separate experiments. Our technique combines elements of traditional cold stage measurements with aspects of flow-through cloud chamber or electrodynamic trap techniques, which allows us to access the temperature range of approximately - 24 ${ }^{\circ} \mathrm{C}$ to 0 and nucleation efficiencies of $10^{-6}$ to 1 .

The temperature range of the system is currently limited by the temperature at which pure water droplets on the silanized glass slides freeze $\left(\sim-25{ }^{\circ} \mathrm{C}\right)$. We are exploring methods to suspend relatively large droplets $(\sim 1 \mathrm{~mm})$ in an acoustic levitator to circumvent this, though we note that the determination of $E$ is even more difficult in that case than what we have described here. To alleviate that difficulty we are attempting to develop optical methods which will enable detection of single aerosol particledroplet collisions. The size of the aerosol particles that we can test using our technique is also limited. Anything larger than about $10 \mathrm{mi}-$ crons diameter settles or impacts out. (Our tests show that we lose a lot of the 10 micron particles before they reach the CINC.) Orienting the flow path in the vertical will solve most of those problems; such a modification is being designed.

The technique we have developed to quantify the efficiency with which aerosol particles in the size range $0.3 \mu \mathrm{m}<\mathrm{D}_{p}<10 \mu \mathrm{m}$ catalyze freezing in the contact mode will improve our understanding of ice processes in mixed phase clouds. For example, we are currently evaluating contact freezing efficiencies for mineral dusts of atmospheric relevance. Currently, most cloud models do not include parameterizations of contact freezing which are well constrained by measure- 
ments (Yun and Penner 2012). Laboratory data such as what we have shown here will narrow the uncertainties associated with ice processes. Additionally, our technique could be adapted for use in the field, though an aerosol concentrator would probably be necessary in that case to improve the signal to noise ratio.

Acknowledgments.

This work was funded through the National Science Foundation, AGS-1028998, AGS-1039742, and AGS-1119164. Swarup China acknowledges a NASA Earth and Space Science Graduate Fellowship. Ashima Chhabra, who was funded through the Michigan University College Partnership program in the summer of 2012, helped with some of the ice nucleation tests with $P$. syringae.

\section{APPENDIX}

\section{Dust dispersal system}

Aerosol is generated via a vibrating membrane upon which dust is placed. The membrane is enclosed and dry HEPA filtered air is pulled through the sealed volume. The lofted particles are then carried to the rest of the experiment. The vibrating membrane is driven by a 4" full range audio speaker. A Wavetek $2 \mathrm{MHz}$ Function Generator (model 20) drives the speaker with a $100 \mathrm{~Hz}$ sine wave amplified through a Memorex 2Xtreme radio circuit. The voltage output of the function generator determines the power of the speaker, and subsequently the number concentration of the aerosol. Numbers from 10 to 1000 per $\mathrm{cm}^{3}$ are readily achieved depending on the dust type. A schematic is shown in Figure 9. The thin membrane is a heat shrinkable plastic available from Henkel Consumer Adhesives, Inc. as part of a Window Kit.

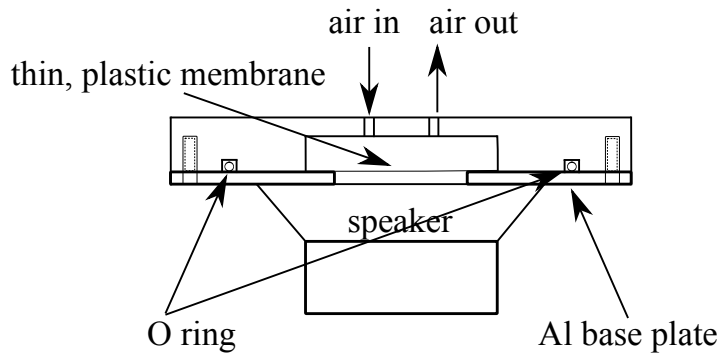

FIG. 9. Schematic of the dust dispersal system. The speaker drives oscillations in the thin membrane; the vibrating membrane lofts the aerosol particles into the air stream.

\section{REFERENCES}

Bundke, U., B. Nillius, R. Jaenicke, T. Wetter, H. Klein, and H. Bingemer, 2008: The fast ice nucleus chamber FINCH. Atmos. Res., 90, 180-186, doi:10.1016/j.atmosres.2008.02.008.

Finke, H., M. Gross, G. Waddington, and H. Huffman, 1954: Low-temperature thermal data for the nine normal paraffin hydrocarbons from octane to hexadcane. J. Am. Chem. Soc., 76, 333-341.

Fletcher, A. N., 1972: High-temperature contact nucleation of supercooled water by organic chemicals. J. Appl. Meteorol., 11, 988-993, doi:10.1175/15200450(1972)011;0988:HTCNOS $¿ 2.0 . C O ; 2$.

Fornea, A., S. Brooks, J. Dooley, and A. Saha, 2009: Heterogeneous freezing of ice on atmospheric aerosols containing ash, soot, and soil. J. Geophys. Res., 114, 011958.

Gokhale, N. and J. Goold, Jr., 1968: Droplet freezing by surface nucleation. J. Appl. Meteorol., $\mathbf{7}, 870-874$.

Hartmann, S., S. Augustin, T. Clauss, H. Wex, T. antl Temkiv, J. Voigtlnder, D. Niedermeier, and F. Stratmann, 2013: Immersion freezing of ice nucleation active protein complexes. Atmos. Chem. Phys., 13, 5751-5766, doi:10.5194/acp-13-5751-2013. 
Hoffmann, N., A. Kiselev, D. Rzesanke, D. Duft, and T. Leisner, 2013: Experimental quantification of contact freezing in an electrodynamic balance. Atmos. Meas. Tech., 6, 23732382, doi:10.5194/amt-6-2373-2013.

Hussain, K. and C. P. R. Saunders, 1984: Ice nucleus measurement with a continuous flow chamber. Q. J. Royal Meteor. Soc., 110, 7584, doi:10.1002/qj.49711046307.

Ladino, L., O. Stetzer, F. Lüönd, A. Welti, and U. Lohmann, 2011: Contact freezing experiments of kaolinite particles with cloud droplets. J. Geophys. Res., 116, 12 PP., doi:201110.1029/2011JD015727.

Ladino, L. A., O. Stetzer, and U. Lohmann, 2013: Contact freezing: a review. Atmos. Chem. Phys. Discuss., 13, 7811-7869, doi:10.5194/acpd-13-7811-2013.

López, M. L. and E. E. Ávila, 2013: Measurements of natural deposition ice nuclei in crdoba, argentina. Atmos. Chem. Phys., 13, 3111-3119, doi:10.5194/acp-13-3111-2013.

Maki, L. R., E. L. Galyan, M.-M. Chang-Chien, and D. R. Caldwell, 1974: Ice nucleation induced by pseudomonas syringae. Appl. Microbiol., 28, $456-459$.

Monier, J.-M. and S. E. Lindow, 2003: Pseudomonas syringae responds to the environment on leaves by cell size reduction. Phytopathology, 93, 1209-1216, doi:10.1094/PHYTO.2003.93.10.1209.

Pitter, R. and H. Pruppacher, 1973: A wind tunnel investigation of freezing of small water drops falling at terminal velocity in air. Q. J. Roy. Meteorol. Soc., 99, 540-550.

Roberts, P. and J. Hallett, 1968: A laboratory study of the ice nucleating properties of some mineral dusts. Q. J. Royal. Met. Soc., 94, 2534 .

Rogers, D., 1988: Development of a continuous flow thermal gradient diffusion chamber for ice nucleation studies. Atmos. Res., 22, 149181.

Shaw, R., A. Durant, and Y. Mi, 2005: Heterogeneous surface crystallization observed in undercooled water. J. Phys. Chem. B, 109, 9865-9868.

Svensson, E., C. Delval, P. von Hessberg, M. Johnson, and J. Pettersson, 2009: Freezing of water droplets colliding with kaolinite particles. Atmos. Chem. Phys., 9, 4295-4300.

Tomlinson, E. M. and N. Fukuta, 1985: A new horizontal gradient, continuous flow, ice thermal diffusion chamber. J. Atmos. Oceanic Technol., 2, 448-467, doi:10.1175/15200426(1985)002¡0448:ANHGCF ¿2.0.CO;2.

Yun, Y. and J. E. Penner, 2012: Global model comparison of heterogeneous ice nucleation parameterizations in mixed phase clouds. J. Geophys. Res., 117, doi:10.1029/2011JD016506. 


\section{Chapter 4}

\section{Laboratory measurements of \\ contact freezing by dust and}

bacteria at temperatures of mixed phase clouds

The material contained in this chapter was previously published in Journal of Atmospheric Science. The work is copyrighted by the American Meteorological Society and is reprinted with permission. 


\title{
Laboratory measurements of contact freezing by dust and bacteria at temperatures of mixed phase clouds
}

\author{
Joseph Niehaus \\ Atmospheric Sciences Program, Michigan Technological University, Houghton, Michigan \\ JENNIFER BECKER \\ Civil and Environmental Engineering, Michigan Technological University, Houghton, Michigan \\ Alexander Kostinski and Will Cantrell * \\ Atmospheric Sciences Program and Physics, Michigan Technological University, Houghton, Michigan
}

\begin{abstract}
We present laboratory measurements of freezing by aerosol particles in the contact mode. We have quantified the fraction catalyzing freezing for three mineral dusts and three strains of bacteria. This is the most comprehensive such dataset to date for temperatures greater than $-20^{\circ} \mathrm{C}$, relevant for warm, mixed phase clouds. For Arizona Test Dust, feldspar, or rhyolitic ash, more than $10^{3}$ particles are required to initiate a freezing event at $-20^{\circ} \mathrm{C}$ in the contact mode. At $-15{ }^{\circ} \mathrm{C}$, more than $10^{5}$ particles are required. An ice negative strain of Pseudomonas fluorescens is an order of magnitude more effective than the mineral dusts at every temperature tested. To the best of our knowledge, this is the first measurement of contact mode freezing by an ice negative bacterium. We find that an ice positive strain of Pseudomonas syringae reaches its maximum nucleating efficiency, $E=0.1$, twelve degrees higher than does Pseudomonas fluorescens. This is consistent with the behavior of ice negative and positive bacteria in the immersion mode, as discovered 40 years ago (Maki et al. 1974; Vali et al. 1976). Surprisingly, cells of the ice positive strain Pseudomonas syringae CC94 which do not express the ice nucleation active gene showed no contact freezing activity, whereas the cells of the ice negative strain of Pseudomonas fluorescens showed significant activity.
\end{abstract}

\section{Introduction}

Ice formation in the troposphere usually proceeds through heterogeneous pathways, where the presence of a foreign substance catalyzes freezing for supercooled cloud droplets. However, in mixed phase clouds ice has been observed to form and persist under conditions indicative of heterogeneous nucleation that have yet to be replicated in laboratories (Hoose and Möhler 2012; Ladino Moreno et al. 2013). The details of how ice is initiated and sustained in those warmer clouds are still elusive. Lohmann (2002) and Korolev et al. (2003), for example, find that the deposition and immersion modes of ice nucleation are inactive for the temperatures of mid-tropospheric clouds. The number of particles that trigger freezing (commonly called ice nuclei, IN) in the immersion mode was too low to account for all the ice particles observed. The contact mode has been found to catalyze freezing for higher temperatures than immersion mode and may contribute to warm tropospheric ice formation, but quantitative data by which that hypothesis could be tested are lacking (Yun and Penner 2012).

In contact nucleation, a solid particle catalyzes freezing of a supercooled liquid by being in contact with the liquid's surface, whereas the immersion mode is characterized by the particle's complete submersion within the liquid. Direct comparison of the contact and immersion mode has shown that the contact mode is more effective for temperatures down to $-34^{\circ} \mathrm{C}$ (Hoffmann 
et al. 2013a; Fukuta 1975; Pitter and Pruppacher 1973; Ladino et al. 2011; Fornea et al. 2009). However, the role of contact nucleation remains to be parameterized in a physically motivated way due to a lack of reproducible results in the laboratory and an incomplete theoretical basis for the mechanism.

The earliest experiments with contact freezing showed that it was effective at higher temperatures than was the immersion mode, but the number of particle-droplet interactions was not well documented in those studies (Gokhale and Goold, Jr. 1968). Subsequent studies provided constraints on the number and size of particles required to initiate freezing (Pitter and Pruppacher 1973; Fukuta 1975), though uncertainties were still substantial. More recent investigators have approached the problem with the explicit goal of quantifying the number of particle-todroplet collisions leading to freezing, with varying degrees of success (Svensson et al. 2009; Ladino et al. 2011; Bunker et al. 2012; Hoffmann et al. 2013b). The efficiencies (explained in Section $2 \mathrm{~b}$ ) reported by different experiments still show a wide variability which have prevented an accurate assessment of contact nucleation in the atmosphere.

Little is known about contact mode nucleation by mineral dust and other inorganic substances, and even less is known about the effectiveness of biological ice nucleators in the contact mode (Levin and Yankofsky 1983). A wide range of organisms and biological materials can act as ice nucleators (Després et al. 2012); however, bacteria may be among the most important biological ice nucleators in the atmosphere because they have relatively long atmospheric residence times (due to their small size relative to other biological material like pollen grains), and they can nucleate ice at temperatures up to $-2.5^{\circ} \mathrm{C}$. Only a few fungal species are known to nucleate ice at comparable temperatures. A growing number of bacteria isolated from air, precipitation, and other habitats have been shown to exhibit ice nucleation properties. However, the most effective ice nucleating bacteria isolated so far are affiliated with four genera within the Gammaproteobacteria: Pseudomonas, Er- winia, Xanthomonas, and Pantoea (Joly et al. 2013). These organisms generally grow in association with plants, and many strains are plant pathogens.

The ice nucleating activity of these bacteria is catalyzed by a protein located on the cell's outer membrane. Although ice formation may be catalyzed by a single ice-nucleating protein at -12 ${ }^{\circ} \mathrm{C}$, a large aggregate of proteins, which is stabilized by the outer membrane, is required to nucleate ice at a temperature of $-3{ }^{\circ} \mathrm{C}$ (Lagriffoul et al. 2010). Thus, whole bacterial cells may be needed to cause freezing at the highest temperatures. Several factors may affect the size of the ice nucleating protein complex, e.g., the composition of the culture medium and the conditions under which the bacteria were grown and/or stored. Furthermore, not every cell of a given strain will contain the protein responsible for ice nucleation at a given time. The fraction of cells that nucleate ice ranges from approximately $10^{-8}$ to close to 1 in different strains (Després et al. 2012). Therefore, ice nucleating bacteria exhibit a wide range of efficiencies at different temperatures.

We report, based on laboratory experiments, the amount of aerosol that impacts the surface of a supercooled water droplet before catalyzing freezing, in terms of both number of particles and total surface area collected. We find that mineral dusts (Arizona Test Dust (ATD), feldspar, and rhyolitic ash) in the size range of 0.3 to $10 \mu \mathrm{m}$ are particularly poor contact nucleators for temperatures $-15^{\circ} \mathrm{C}$ to $-22^{\circ} \mathrm{C}$. The ice negative bacterium Pseudomonas fluorescens strain A506 is a more effective ice nucleator than any of the mineral dusts. Snomax ${ }^{\mathrm{TM}}$ (Snomax International), Pseudomonas syringae, is the most active and can form ice up to temperatures of $-3.0^{\circ} \mathrm{C}$. Another ice positive $P$. syringae strain (CC94), showed no contact mode freezing behavior. 


\section{Methods}

\section{a. Measurement}

To measure ice nucleation, we employ a cold stage to supercool water droplets before exposing them to aerosol for particle-droplet interactions. We briefly explain the technique here, but it is described in more detail in Niehaus et al. (2013). A $5 \mu$ l water droplet (HPLC grade) is placed on a silanized glass slide which sits atop a temperature-controlled copper stage, the contact ice nucleation chamber or CINC. The droplet is supercooled to a specified temperature and allowed to equilibrate with its surroundings. Aerosol is then generated by dispersing dry dust via a vibrating membrane. Filtered air flows through the volume above the vibrating membrane, picking up particles. The aerosol flow is cooled with a heat exchanger, and then directed across the droplet. Some of the particles in the air stream deposit to the droplet, thereby allowing us to evaluate contact freezing. The phase of the droplet is monitored via a $1 \mathrm{~mW}$ diode laser focused through the droplet and into a photodiode. When the droplets freeze, the laser beam is scattered and a corresponding drop in signal is observed.

The number of particles that deposit to the droplet is obtained by examining the residue of some test droplets with a scanning electron or optical microscope, similar to the empirical measures employed by Hoffmann et al. (2013b). $5 \pm$ 3 out of every thousand particles are deposited to the droplet (Niehaus et al. 2013). Knowing the fraction of aerosol particles that deposit to the droplet, we can determine the number of particles which have collided with a test drop simply by measuring the number of particles passing through the system. That is done with a TSI Optical Particle Sizer (OPS) 3330 which reports particle counts with an uncertainty of $10 \%$.

Once particles are on the surface of the droplet they could be swept into the interior by air currents or diffusion, conceivably then leading to immersion freezing. To eliminate contributions to nucleation from the immersion mode, we ran experiments in which we sampled aerosol for some time, ensuring that particles were deposited to the droplet. We then switched to a particle free flow, observing the unfrozen droplet. We detected no freezing events in any of those cases, despite the fact that there were particles immersed in the droplet. As a further control, in some tests, droplets which had frozen by contact nucleation were melted, then cooled back to the original temperature, where freezing was originally observed. The supercooled droplets were then held at constant temperature for an hour with no aerosol flow; in those cases, the test droplets did not freeze. These tests indicate that the freezing events we observe are the result of a particle-droplet collision, not merely the presence of aerosol particles within the droplet or at its surface.

Because the droplet sits on a glass slide, the surface provides a bound on the achievable supercooling. The heterogeneous freezing temperature due to the glass slide is $249.75 \mathrm{~K}(-23.5$ $\left.{ }^{\circ} \mathrm{C}\right)$, and control tests with droplets can be set to $250.25 \mathrm{~K}\left(-23{ }^{\circ} \mathrm{C}\right)$ with no observed freezing events. Tests are performed at constant temperature with aerosol flowing past the droplet for 30 minutes or until a freezing event is observed. Droplets do not evaporate appreciably during this time period, which minimizes changes in the geometry of the system that might affect collision rates of aerosol particles. The number of aerosol particles that collide with the droplet sets an upper limit to the temperature that we can reasonably explore. If the freezing probability for a single particle-droplet collision is low ( $E<10^{-5}$, see below for definitions), the time required to acquire statistically meaningful data is prohibitive.

Our system is designed as a way to measure the probability that an aerosol particle coming into contact with a surface of supercooled water will result in a freezing event. The test droplets which we employ are much, much larger than typical cloud droplets, which are $\sim 10 \mu \mathrm{m}$ in diameter. However, insofar as surface curvature does not play a role in the mechanism of con- 
tact nucleation, our measurements are applicable to the case of aerosol particles interacting with cloud droplets. Similarly, aerosol particles in clouds are collected by droplets by thermodiffusiophoresis and gravitational settling of the cloud droplets in a turbulent flow, whereas in the CINC, the particles diffuse and settle out of the airstream onto the test droplets. Finally, clouds are also close to saturation, whereas the airflow in the CINC is dry. Aerosol particles which come into contact with the test droplet must, however, pass through a saturated vapor field surrounding the droplet. Cooper (1974) estimated that the water adsorbed to an aerosol particle would come into equilibrium with a vapor field within $10^{-4}$ seconds, so we are confident that the particles which hit the test droplets are representative of particles with adsorbed water in a cloud. For a more comprehensive discussion of the distinction between laboratory experiments and contact freezing in clouds, see Ladino Moreno et al. (2013).

\section{b. Freezing Efficiency}

Contact ice nucleation is quantified by the number efficiency, $E$, defined as the ratio of freezing events $F$ to the number of particles $N$ on or in the droplet,

$$
E=\frac{F}{N} .
$$

We interpret an efficiency of $10^{-3}$ to mean that 1 in every 1000 particle impacts results in the droplet freezing.

Heterogeneous nucleation is generally related to surface area, expressed in units of freezing events per (time $\times$ area) (Lamb and Verlinde 2011). Therefore we have also quantified the efficiency in terms of surface area via,

$$
S E=\frac{F}{S_{A}},
$$

where $S E$ is the number of freezing events per total surface area deposited to the test droplet, $S_{A}$. In essence, $S E$ is the active site density in the contact mode. Note that we are implicitly adopting a singular model in that we assume that a particle which catalyzes freezing in the contact mode does so immediately upon interaction with the surface of the droplet; i.e. there is no time dependence.

\section{c. Samples}

Arizona Test Dust (Powder Technologies Inc) was chosen because it is well studied and compositionally similar to the dust in many deserts. K-Feldspar's importance was recently quantified by Atkinson et al. (2013), who proposed that the fraction of feldspar in dust dominates a sample's immersion nucleation rate. Rhyolitic ash is volcanic in origin and is known to be glassy; Energy Dispersive X-Ray Spectroscopy showed our sample to contain a majority of $\mathrm{SiO}_{2}$. Aluminum and sulfur were also present.

Several Pseudomonas syringae strains have been well characterized in terms of their ice nucleating ability (Levin and Yankofsky 1983; Maki et al. 1974), and therefore, two of them were included in the present study. Snomax ${ }^{\mathrm{TM}}$ is a commercially available product which is added to water to facilitate snowmaking. Strain 31a (ATCC 53543) is presumed to be used in the production of Snomax $^{\mathrm{TM}}$ (Lagriffoul et al. 2010). Freeze-dried cells that are killed via irradiation comprises the finished product. The cells are mostly intact, but Snomax ${ }^{\mathrm{TM}}$ also includes cell debris and dried culture medium (Morris 2012). P. syringae CC94 was obtained from David Sands (Montana State University) and maintained as described below. BlightBan $^{\mathrm{TM}}$ (Nufarm Americas) is a biological control agent intended to reduce damage to fruit trees caused by fire blight and frost; it consists of Pseudomonas fluorescens strain A506 that naturally lacks the gene responsible for high temperature ice nucleation.

P. syringae CC94 was routinely maintained at 
$20{ }^{\circ} \mathrm{C}$ on agar plates prepared with King's medium B (KB, King et al. (1954)). Freezedried P. syringae CC94 cells were prepared from suspended cultures grown overnight in KB broth in a shaking incubator maintained at $20{ }^{\circ} \mathrm{C}$ and $160 \mathrm{rpm}$. The cultures were centrifuged at 6000 rpm for $15 \mathrm{~min}$, and the resulting pellet was resuspended in sterile water (1-mL) and transferred to $12-\mathrm{mL}$ conical glass tubes. The aqueous cell suspension was shell frozen in a dry ice and acetone bath and then lyophilized. The freeze dried pellets were gently crushed with a mortar and pestle to facilitate aerosolization in the vibrating membrane dust generator.

As noted above, all samples are dry dispersed using a vibrating plastic membrane into a filtered air stream with a dew point less than $40^{\circ} \mathrm{C}$. The samples which we observe with the OPS are a convolution of the original dust, the efficiency with which that dust is lofted in the air stream by the vibrating membrane, and the efficiency with which the airborne particles are carried through the sampling lines and the contact IN chamber. Particles in the size range 0.5 $\mu \mathrm{m}<\mathrm{D}_{p}<8.0 \mu \mathrm{m}$ dominate the number distributions which we measure.

\section{Results and Discussion}

The two plots shown in Figure 10 are number (upper panel) and surface area (lower panel) efficiencies for the dust and bacteria. One conclusion evident from both plots is that a lot of dust needs to impact the surface before a freezing event occurs. At $-20^{\circ} \mathrm{C}$, only 1 in $\sim 10^{4}$ mineral dust particles will catalyze freezing, which seems to contradict earlier work that showed mineral dusts were effective in the contact mode at temperatures as high as $-4{ }^{\circ} \mathrm{C}$ (Gokhale and Goold, Jr. 1968; Gokhale and Spengler 1972; Fukuta 1975; Pitter and Pruppacher 1973). The earlier results, however, rarely quantified how many particles were necessary to initiate the phase transition. In some cases, the dusts were manually sprinkled over droplets on a cold plate; as a result there were undoubtedly many more particles on the surface of their test droplets than
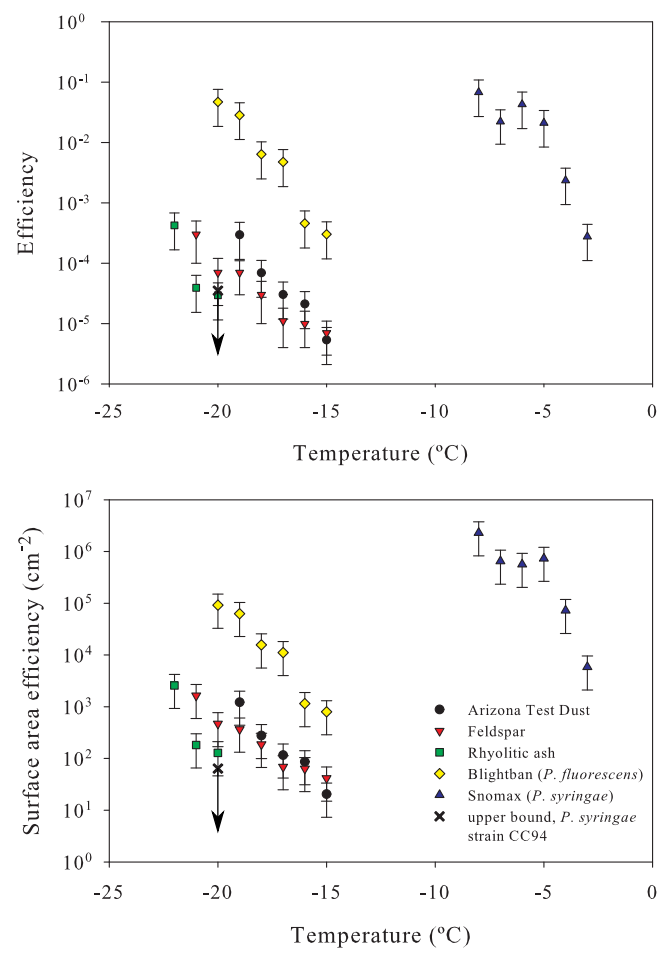

FIG. 10. Upper panel. The freezing efficiency, $E$, for three mineral dusts and three samples of bacteria. The mineral dusts are relatively inefficient ice nucleators in the contact mode for $T>-20{ }^{\circ} \mathrm{C}$. P. fluorescens is two to three orders of magnitude more effective by number at all temperatures tested. Efficiency for $P$. $f l u$ orescens and $P$. syringae is plotted as a function of the number of aerosol particles which collided with the droplet, not the number of cells. Larger particles are most likely clumps of individual cells. The contact freezing limit is shown for the CC94 strain of P. syringae, based on the tests we have run in which no freezing was observed. Snomax ${ }^{\mathrm{TM}}$ (P. syringae) is the most effective high temperature ice nucleator, plateauing at 0.05 by $-8^{\circ} \mathrm{C}$. Lower panel. Surface area freezing efficiency, $S E$, for the same samples as shown in the upper panel. 
are represented in Figure 10.

\section{a. Number Efficiency}

The efficiency by number shown in the upper panel of Figure 10 can be interpreted as the probability that a single particle-droplet collision will result in a freezing event. If it is the collision itself that catalyzes the freezing event, the probability of freezing should scale with the number of aerosol particles that have collided with the supercooled droplet.

All three mineral samples, ATD, feldspar, and rhyolitic ash, had similar nucleating efficiencies across the range of temperatures tested in this study. At $-15^{\circ} \mathrm{C}$, the mineral dusts have an efficiency of $\sim 10^{-5}$, and, as expected, $E$ increases with decreasing temperature. If extrapolated to a temperature of $-32{ }^{\circ} \mathrm{C}$, the dust would have an efficiency of 0.01. In comparison, Hoffmann et al. (2013a) report freezing efficiencies ranging from 0.04 to 0.4 for illite particles with mobility diameters ranging from $322 \mathrm{~nm}$ to $750 \mathrm{~nm}$, respectively.

The bacterium P. fluorescens A506 had higher efficiencies than the dusts at all of the temperatures evaluated, with $E \simeq 0.05$ at $-20{ }^{\circ} \mathrm{C}$. This result is especially striking when considering that this particular strain of $P$. fluorescens is ice negative; it does not possess the gene necessary for synthesis of the ice nucleating protein in the cell membrane. While there are strains of $P$. fluorescens that are ice positive and exhibit high temperature ice nucleation, they were not included in this study. Our results with strain A506 are remarkable because they suggest that some ice negative bacteria may be more effective than dust in their ice nucleating efficiency for $-15>T>-20{ }^{\circ} \mathrm{C}$.

Two strains of $P$. syringae were also tested and found to have widely varying efficiencies. Both are ice positive, as determined by nucleation tests in the immersion mode and in comparison to the results reported by Maki et al. (1974).
Snomax ${ }^{\mathrm{TM}}$ starts to exhibit ice nucleating activity in the contact mode at $-2.5^{\circ} \mathrm{C}$, rising to $\mathrm{E}$ $=0.1$ by $-8^{\circ} \mathrm{C}$. Some previous work with biological ice nucleators such as Snomax ${ }^{\mathrm{TM}}$ showed that they contain an average of one nucleation site per bacterial cell (Lagriffoul et al. 2010), but more recent experiments have indicated a maximum activated fraction in the immersion mode of 0.2 to 0.4 (Hartmann et al. 2013). In contrast, strain CC94 showed no freezing events in the contact mode, at temperatures down to -20 ${ }^{\circ} \mathrm{C}$. The upper limit for $E$ and $S E$ for strain CC94 are shown with an "x" in Figure 10.

Even though P. syringae strain CC94 is ice positive, not every cell within a population expresses the ice nucleation gene, leading to the formation of the ice nucleating protein at a given time. Previous work has shown that the immersion freezing threshold decreases with a decreasing number of cells in a test droplet droplet (Maki et al. 1974). Following Maki et al.'s procedure of determining the freezing temperatures of serial dilutions of samples, we have determined that the fraction of cells in our sample of CC94 which express the ice nucleation active gene is $2 \times 10^{-6}$ (data not shown). This small fraction makes a statistically valid determination of $E$ for CC94 time prohibitive. The fact that we see no contact nucleation from this strain at $-20{ }^{\circ} \mathrm{C}$ also indicates that the cells of $P$. syringae CC94 that do not express the ice nucleation active gene are not as effective in the contact mode as are the P. fluorescens A506 (BlightBan) cells, which are naturally deficient in the gene. However, we cannot rule out the possibility that the physical or chemical characteristics of the various bacterial samples influenced the results. For example, the freeze-dried samples of $P$. syringae CC94 used in this study were ground with a mortar and pestle, and this likely disrupted the association of the ice nucleation protein with the cell membrane that appears to be critical in maintaining the ice nucleating capabilities of $P$. syringae strains at warmer temperatures in many cells. On the other hand, according to information provided by the manufacturer, the $P$. fluorescens A506 (Blightban) samples contain $29 \%$ inactive ingredients, which is presumably primarily culture media components that would have depressed 

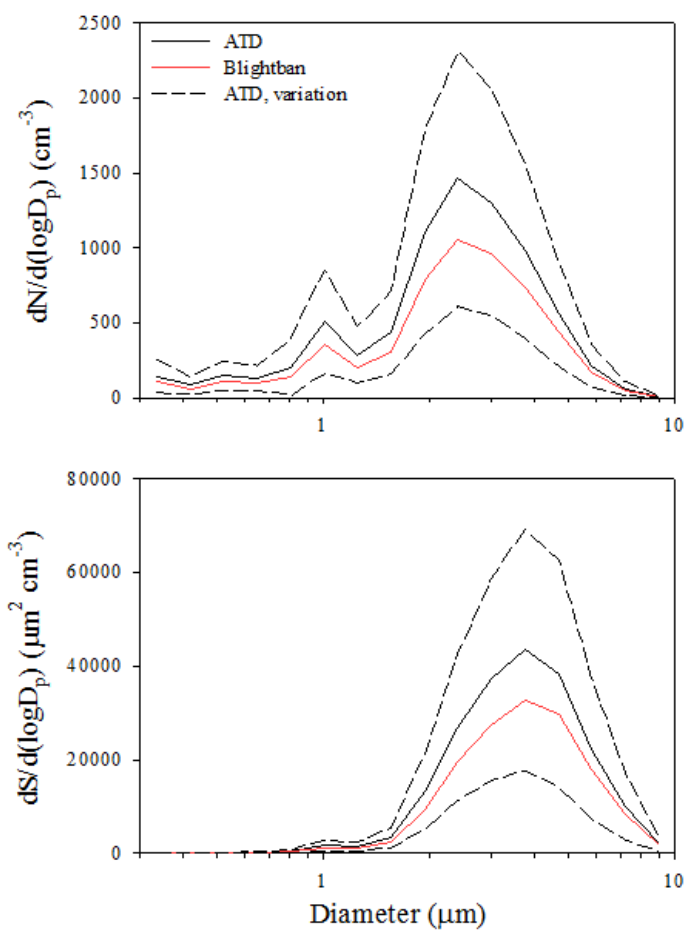

FIG. 11. Representative number (upper panel) and surface area (lower panel) distributions for ATD and Blightban for a single experiment. The other dusts had similar number distributions. The mean is shown as a line; variation about the mean for the ATD (one standard deviation) during the experiment is shown with dashed lines. Variation about the mean was similar for other dusts.

the freezing temperature of these samples. In contrast, the $P$. syringae CC94 cells used in this study were suspended in distilled and deionized water prior to freeze-drying. Nevertheless, these results highlight the inherent variability in the ice nucleating efficacy of biological material.

\section{b. Surface Area Efficiency}

As noted above, the efficiency can be interpreted as the probability that a single collision between an aerosol particle and a supercooled droplet of water will result in a freezing event. This interpretation is valid if it is solely the impact with the surface that catalyzes the freezing event. If however, there is some property of the surface of the aerosol particle which catalyzes the phase transition upon contact with the surface of the supercooled droplet of water, then the number of observed freezing events should scale with the surface area of the particles which have been deposited to the droplet.

To that end, consider Figure 11, which shows representative number distributions (upper panel) and surface area distributions (lower panel) for Arizona Test Dust and Blightban, as sampled by the OPS after the contact IN chamber. As noted in Section 2c, the distributions that pass through the CINC and are observed by the OPS are a convolution of their representation in the parent sample, the probability that they are lofted into the airstream by the membrane, and their penetration efficiency through the sample system. The latter two dominate, so it is not surprising that the distributions for all of the dusts we sampled are similar. That, however, facilitates comparison of their contact efficiencies.

The mode of the number distribution is at a diameter of $\sim 2.5 \mu \mathrm{m}$, with a secondary peak at one $\mu \mathrm{m}$. The secondary peak is much less important for the surface area, and the peak of the distribution shifts to $\sim$ four $\mu \mathrm{m}$. As expected, larger particles assume a greater importance, though the number of the largest particles (eight to $10 \mu \mathrm{m}$ in diameter) is still so small that they contribute little to the overall surface area.

The surface area reported in the lower panel of Figure 11 is the geometric surface area, derived from the particle diameters reported by the OPS. For spherical particles of a specified index of refraction, the scattering signal is well known (Bohren and Huffman 1998). Mineral dust particles, are however, not spherical; they have irregular shapes. We do not have the ability to correct for asphericity, and so report the surface area of the spheres. Mineral dust particles may also absorb incident radiation, which skews the size reported by the OPS which is calibrated with polystyrene latex spheres. We used the OPS's internal correction for the index of re- 
fraction together with optical constants for ATD reported by Glen and Brooks (2013) to estimate the uncertainty associated with using the surface area derived from the standard calibration. Using the optical constants which include absorption shifts the diameters to a slightly higher value $(\sim 10 \%)$, which results in the total surface area increasing by approximately $15 \%$, well within the range of the uncertainty shown in the lower panel of Figure 10. (We do not have optical constants for all the dusts, and so cannot correct them all for absorption effects.)

The data for $S E$ in the lower panel of Figure 10 show features similar to those exhibited by $E$, the number efficiency. At $-15{ }^{\circ} \mathrm{C}$, for every square centimeter of mineral dust surface area, deposited to the surface of a test droplet, there are 20 freezing events, rising to more than 1000 $\mathrm{cm}^{-2}$ at $-20{ }^{\circ} \mathrm{C}$. P. fluorescens A506 (BlightBan) is, again, clearly separated from the inorganic particles; for a given quantity of material of the same size, for a given temperature, it is more than an order of magnitude more likely to catalyze freezing than are the mineral dusts. The BlightBan can nucleate ice at $-15^{\circ} \mathrm{C}$ with $S E=10^{3} \mathrm{~cm}^{-2}$, whereas mineral dust requires almost five additional degrees of cooling to achieve the same efficiency.

\section{Atmospheric Relevance}

As Figure 10 shows, few of the mineral dust particles are effective as contact freezing nuclei in the temperature range -15 to $-20{ }^{\circ} \mathrm{C}$. Contact freezing is unlikely for a single particledroplet collision, but our tests show that immersion freezing is even less likely (see Section 2 ) in that temperature range. (See also results in Hoffmann et al. (2013b).) As an upper limit on the production of ice by contact freezing by the dusts, consider a dust concentration of 1 $\mathrm{cm}^{-3}$ (DeMott et al. 2003) in a cloud with a droplet concentration of $100 \mathrm{~cm}^{-3}$ (Lamb and Verlinde 2011, Chpt. 1). Further assume that every dust particle is eventually collected by a cloud droplet during the lifetime of the cloud. At $-20{ }^{\circ} \mathrm{C}, E$ is just over $5 \times 10^{-4}$ for the min- eral dusts. For simplicity we will round this to $E=10^{-3}$ which leads to 1 nucleation event by the contact mechanism for every liter of cloudy air. Field observations of the number concentration of ice crystals produced by nucleation, not secondary mechanisms, in clouds ranges from $\sim$ 0.01 to $10 \mathrm{l}^{-1}$ of cloudy air at $-20{ }^{\circ} \mathrm{C}$ (Lamb and Verlinde 2011, pg. 459).

Bacteria have the potential to be more significant IN. The efficiencies for P. fluorescens A506 reported here are, on average, more than an order of magnitude higher than those of the mineral dusts. The number concentrations of bacteria in the atmosphere are much more uncertain. However, if we estimate that the number concentration of bacteria is $100 \times$ lower than mineral dust (Phillips et al. 2008, Appendix C), that would still yield approximately one nucleation event per 2 liters of cloudy air at -20 ${ }^{\circ} \mathrm{C}$. Snomax ${ }^{\mathrm{TM}}$ would produce 10 ice crystals per liter at $-10{ }^{\circ} \mathrm{C}$. The high temperature freezing events $\left(\mathrm{T}>-10{ }^{\circ} \mathrm{C}\right)$ are particularly interesting because they occur in the temperature range of the most well documented ice multiplication process, Hallett-Mossop. While these simple back-of-the-envelope examples do not prove that contact nucleation will lead to ice formation at temperatures of mixed phase clouds, it does, at least, suggest that contact nucleation may play a role. More definitive conclusions will probably only be possible by incorporating realistic contact nucleation parameterizations into cloud modeling studies.

Finally, Figure 12 is a comparison between our mineral dust and $P$. fluorescens data and a parameterization of naturally occurring ice nuclei. Our data are shown as two best-fit lines, while the parametization is from Phillips et al. (2008), which is based on measurements of ice nuclei and the surface area of natural aerosol. The parameters for the best fit lines to our data are shown in Table 4. We used representative number distributions to derive the activated fraction from the parameterization for comparison to our freezing efficiencies. Note that Phillips et al. (2008) is based on measurements made with a continuous flow diffusion chamber, which has an upper limit of one micron. The active fractions reported 


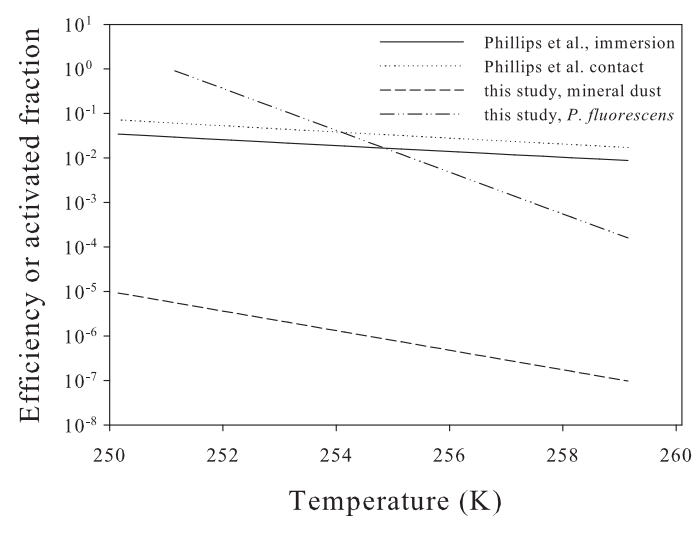

FIG. 12. Comparison of the data presented in this study with the parameterization from Phillips et al. (2008), based on measurements of submicron aerosol particles in the atmosphere. The activated fraction (our efficiency) of the mineral dust is three to five orders of magnitude lower than either the parameterized immersion or contact mode from Phillips et al. (2008) across the temperature range for which our measurements are valid.

here are biased high because we used values of the surface area and total number of aerosol particles derived from our measurements, which are dominated by particles with diameters greater than one micron.

Comparison of our data to the parameterization from Phillips et al. (2008) suggests that dust aerosol in the atmosphere is three to five orders of magnitude more likely to catalyze a freezing event than are the laboratory generated dust aerosol. One to three percent of naturally occurring aerosol particles initiate freezing while the efficiency of contact nucleation that we measured ranges from $10^{-5}$ to $10^{-7}$. Though our efficiencies are much smaller than those derived from the formulation of Phillips et al., the temperature sensitivity is much greater, increasing by two orders of magnitude over nine degrees, whereas the parameterization increases by only a factor of four. Though our P. fluorescens efficiencies are roughly $10 \times$ lower than the frozen fractions from Phillips et al. (2008) for mineral dust at $-14{ }^{\circ} \mathrm{C}$, they exceed the values at the lowest temperatures tested.
TABLE 4. Parameters for the best fit lines to the mineral dust and $P$. fluorescens contact nucleation data. The lines are of the form $\log (E)=b+a T$. We have grouped the mineral dust together; the individual data sets are similar enough as to be represented by a single line.

\begin{tabular}{lll}
\hline \hline Substance & intercept & slope \\
\hline Mineral dust & $50 \pm 10$ & $-0.22 \pm 0.04$ \\
$P$. fluorescens & $120 \pm 10$ & $-0.47 \pm 0.05$ \\
\hline
\end{tabular}

The contrast between the efficiencies we measure for the dust and those predicted by Phillips et al.'s parameterization highlights the need for further investigation of this topic. Figure 12 clearly shows a large discrepancy between measured and predicted rates of contact nucleation, though the freezing efficacy of an ice negative bacterium that we document in this study may provide an avenue for resolution. Recent work (Conen et al. 2011; O'Sullivan et al. 2013) indicates that material which would be classified as mineral dust in the scheme of Phillips et al. (2008) may have ice nucleating activity from the biological residues associated with it.

\section{Conclusions}

We have quantified the fraction of aerosol particles which catalyze freezing in the contact mode for three mineral dusts and three strains of bacteria for $T \geq-20{ }^{\circ} \mathrm{C}$. For Arizona Test Dust, feldspar, or rhyolitic ash, the freezing efficiency, $E$, is less than $10^{-3}$ for $-20^{\circ} \mathrm{C}$, decreasing to less than $10^{-5}$ at $-15^{\circ} \mathrm{C}$. In contrast to the mineral dusts, an ice negative strain of Pseudomonas fluorescens is an order of magnitude more effective at every temperature tested, rising to $E \simeq$ 0.1 at $-20{ }^{\circ} \mathrm{C}$. Another commercially available bacterium, Snomax ${ }^{\mathrm{TM}}$ (Pseudomonas syringae) reaches that value twelve degrees higher than does the Pseudomonas fluorescens, similar to what is seen with ice negative and positive bacteria in the immersion mode. The cells of Pseudomonas syringae CC94 that did not express the ice nucleating gene, showed no contact freezing 
activity, whereas the ice negative strain of Pseudomonas fluorescens did, which highlights the inherent variability within biological material.

Our contact nucleation efficiencies for mineral dust are three to five orders of magnitude lower than those derived from a parameterization of ice nucleation activity in the contact mode as determined from field measurements (Phillips et al. 2008). (The field measurements and parameterization also show significantly higher efficiencies for the immersion mode in the temperature range investigated.) Our measurements of the contact freezing efficiency of both ice positive and negative bacteria may help to explain this discrepancy, as biological material present on atmospheric dusts could increase their efficacy considerably.

Acknowledgments.

This work was funded through the National Science Foundation, AGS-1028998, AGS-1039742, and AGS-1119164. Ashima Chhabra, who was funded through the Michigan University College Partnership program in the summer of 2012, helped with some of the ice nucleation tests with $P$. syringae. Adam Cary cultured the P. syringae CC94 and was funded through funds internal to Michigan Tech, including SURF in the summer of 2013. Thanks also to Adam Durant for giving us the sample of rhyolitic ash; similarly, thanks to Thomas Whale and Benjamin Murray for the sample of feldspar. Thanks to David Sands who provided the sample of $P$. syringae CC94. Nufarm Americas graciously provided a sample of BlightBan A506.

\section{REFERENCES}

Atkinson, J. D., et al., 2013: The importance of feldspar for ice nucleation by mineral dust in mixed-phase clouds. Nature, 498, 355-358.
Bohren, C. and D. Huffman, 1998: Absorption and Scattering of Light by Small Particles. John Wiley \& Sons, New York.

Bunker, K. W., S. China, C. Mazzoleni, A. Kostinski, and W. Cantrell, 2012: Measurements of ice nucleation by mineral dusts in the contact mode. Atmos. Chem. Phys. Discuss., 12 (8), 20 291-20 309, doi:10.5194/ acpd-12-20291-2012.

Conen, F., C. E. Morris, J. Leifeld, M. V. Yakutin, and C. Alewell, 2011: Biological residues define the ice nucleation properties of soil dust. Atmos. Chem. Phys., 11 (18), 9643-9648, doi:10.5194/acp-11-9643-2011.

Cooper, W., 1974: A possible mechanism for contact nucleation. J. Atmos. Sci., 31, 18321837.

DeMott, P. J., K. Sassen, M. R. Poellot, D. Baumgardner, D. C. Rogers, S. D. Brooks, A. J. Prenni, and S. M. Kreidenweis, 2003: African dust aerosols as atmospheric ice nuclei. Geophys. Res. Lett., 30 (14), n/an/a, doi:10.1029/2003GL017410.

Després, V. R., et al., 2012: Primary biological aerosol particles in the atmosphere: a review. Tellus B, 64 (0), doi:10.3402/tellusb. v64i0.15598.

Fornea, A., S. Brooks, J. Dooley, and A. Saha, 2009: Heterogeneous freezing of ice on atmospheric aerosols containing ash, soot, and soil. J. Geophys. Res., 114, 011958.

Fukuta, N., 1975: A study of the mechanism of contact nucleation. J. Atmos. Sci., 32, 15971603.

Glen, A. and S. D. Brooks, 2013: A new method for measuring optical scattering properties of atmospherically relevant dusts using the cloud and aerosol spectrometer with polarization (CASPOL). Atmos. Chem. Phys., 13 (3), 1345-1356, doi:10.5194/acp-13-1345-2013.

Gokhale, N. and J. Goold, Jr., 1968: Droplet freezing by surface nucleation. J. Appl. Meteorol., 7, 870-874.

Gokhale, N. and J. Spengler, 1972: Freezing of freely suspended, supercooled water drops 
by contact nucleation. J. Appl. Meteorol., 11, 157-160.

Hartmann, S., S. Augustin, T. Clauss, H. Wex, T. antl Temkiv, J. Voigtlnder, D. Niedermeier, and F. Stratmann, 2013: Immersion freezing of ice nucleation active protein complexes. Atmos. Chem. Phys., 13 (11), 57515766, doi:10.5194/acp-13-5751-2013.

Hoffmann, N., D. Duft, A. Kiselev, and T. Leisner, 2013a: Contact freezing efficiency of mineral dust aerosols studied in an electrodynamic balance: quantitative size and temperature dependence for illite particles. Faraday Discussions, doi:10.1039/C3FD00033H.

Hoffmann, N., A. Kiselev, D. Rzesanke, D. Duft, and T. Leisner, 2013b: Experimental quantification of contact freezing in an electrodynamic balance. Atmos. Meas. Tech., 6 (9), 2373-2382, doi:10.5194/amt-6-2373-2013.

Hoose, C. and O. Möhler, 2012: Heterogeneous ice nucleation on atmospheric aerosols: a review of results from laboratory experiments. Atmos. Chem. Phys. Discuss., 12 (5), 12 53112 621, doi:10.5194/acpd-12-12531-2012.

Joly, M., E. Attard, M. Sancelme, L. Deguillaume, C. Guilbaud, C. E. Morris, P. Amato, and A.-M. Delort, 2013: Ice nucleation activity of bacteria isolated from cloud water. Atmos. Environ., 70, 392-400, doi:10.1016/j. atmosenv.2013.01.027.

King, E. O., M. Ward, and D. Raney, 1954: Two simple media for the demonstration of pyocyanin aind fluorescin. J. Lab. Clin. Med, 44, 301-307.

Korolev, A. V., G. A. Isaac, S. G. Cober, J. W. Strapp, and J. Hallett, 2003: Microphysical characterization of mixed-phase clouds. Quart. J. Royal Meteorol. Soc., 129 (587), 3965, doi:10.1256/qj.01.204.

Ladino, L., O. Stetzer, F. Lüönd, A. Welti, and U. Lohmann, 2011: Contact freezing experiments of kaolinite particles with cloud droplets. J. Geophys. Res., 116, 12 PP., doi: 201110.1029/2011JD015727.
Ladino Moreno, L. A., O. Stetzer, and U. Lohmann, 2013: Contact freezing: a review of experimental studies. Atmos. Chem. Phys., 13 (19), 9745-9769, doi:10.5194/ acp-13-9745-2013.

Lagriffoul, A., et al., 2010: Bacterial-based additives for the production of artificial snow: What are the risks to human health? Sci. Total Environ., 408 (7), 1659-1666, doi:10. 1016/j.scitotenv.2010.01.009.

Lamb, D. and J. Verlinde, 2011: Physics and Chemistry of Clouds. Cambridge University Press, Cambridge.

Levin, Z. and S. A. Yankofsky, 1983: Contact versus immersion freezing of freely suspended droplets by bacterial ice nuclei. $J$. Climate Appl. Meteorol., 22 (11), 19641966, doi:10.1175/1520-0450(1983)022〈1964: CVIFOF $>2.0 . \mathrm{CO} ; 2$.

Lohmann, U., 2002: A glaciation indirect aerosol effect caused by soot aerosols. Geophys. Res. Lett., 29, 014357.

Maki, L. R., E. L. Galyan, M.-M. Chang-Chien, and D. R. Caldwell, 1974: Ice nucleation induced by pseudomonas syringae. Appl. Microbiol., 28 (3), 456 -459.

Morris, C., 2012: Interactive comment on "hetergeneous ice nucleation on atmospheric aerosols: a review of results from laboratory experiments" by c. hoose and o. möhler. Atmos. Chem. Phys. Discuss., 12, C3025C3027.

Niehaus, J., K. Bunker, S. China, A. Kostinski, C. Mazzoleni, and W. Cantrell, 2013: A technique to measure ice nuclei in the contact mode. J. Atmos. Ocean. Technol., in press.

O'Sullivan, D., et al., 2013: Ice nucleation by soil dusts: relative importance of mineral dust and biogenic components. Atmos. Chem. Phys. Discuss., 13 (8), 20 275-20317, doi: 10.5194/acpd-13-20275-2013.

Phillips, V., P. DeMott, and C. Andronache, 2008: An empirical parameterization of heterogeneous ice nucleation for multiple chemical species of aerosol. J. Atmos. Sci., 65, $2757-2783$. 
Pitter, R. and H. Pruppacher, 1973: A wind tunnel investigation of freezing of small water drops falling at terminal velocity in air. $Q . J$. Roy. Meteorol. Soc., 99, 540-550.

Svensson, E., C. Delval, P. von Hessberg, M. Johnson, and J. Pettersson, 2009: Freezing of water droplets colliding with kaolinite particles. Atmos. Chem. Phys., 9, 4295-4300.

Vali, G., M. Christensen, R. W. Fresh, E. L. Galyan, L. R. Maki, and R. C. Schnell, 1976: Biogenic ice nuclei. part II: bacterial sources. J. Atmos. Sci., 33 (8), 15651570, doi:10.1175/1520-0469(1976)033<1565: BINPIB $>2.0 . \mathrm{CO} ; 2$.

Yun, Y. and J. E. Penner, 2012: Global model comparison of heterogeneous ice nucleation parameterizations in mixed phase clouds. $J$. Geophys. Res., 117 (D7), n/an/a, doi:10. 1029/2011JD016506. 


\section{Chapter 5}

\section{Contact Freezing of Water by Salts}

The material contained in this chapter was previously published in Journal of Physical Chemistry Letters. Reprinted with permission from Niehaus, Joseph, and Will Cantrell. "Contact freezing of water by salts." The journal of physical chemistry letters 6.17 (2015): 3490-3495. http://pubs.acs.org/doi/full/10.1021/acs.jpclett.5b01531. Copyright 2015 American Chemical Society. 


\title{
Contact Freezing of Water by Salts
}

\author{
Joseph Niehaus and Will Cantrell* \\ Atmospheric Sciences Program and Department of Physics \\ Michigan Technological University, Houghton MI 49931 \\ E-mail: cantrell@mtu.edu
}

\begin{abstract}
Water is unlikely to crystallize homogeneously at temperatures greater than $-34{ }^{\circ} \mathrm{C}$. Freezing at higher temperatures is heterogeneous - catalyzed by the presence of a second substance. If that substance is at an air-water interface, the mode is called contact freezing, and it typically will trigger nucleation at a higher temperature than if the substance were wholly immersed within the liquid. We find that the impact of salt particles initiates freezing in experiments using water droplets at supercoolings of 9 to $16{ }^{\circ} \mathrm{C}$. These results show that contact freezing nuclei need not be effective as immersion mode nuclei. We discuss our results in the context of proposed mechanisms of contact freezing. Finally, we use the timescales for diffusion of heat and of ions, and the propagation of a sound wave through the droplet to estimate that contact freezing occurs within 10 ns of impact. ${ }^{1}$
\end{abstract}

\footnotetext{
${ }^{1}$ Reprinted with permission from Niehaus, Joseph, and Will Cantrell. "Contact Freezing of Water by Salts." The journal of physical chemistry letters 6.17 (2015): 3490-3495.. Copyright 2015 American Chemical Society.
} 
At atmospheric pressure, small quantities of pure water can be cooled to approximately $-34{ }^{\circ} \mathrm{C}$ before crystallization spontaneously occurs. However, common experience shows that water will freeze at temperatures much closer to the melting point. Such freezing events are heterogeneous and are triggered by the presence of a second substance which acts as a catalyst, reducing the free energy barrier between the metastable, supercooled water and ice. The degree to which the second substance catalyzes the phase transition varies considerably. Self assembled monolayers of long chain alcohols can initiate freezing at a supercooling of only one degree ${ }^{1}$ while some mineral dusts may not become effective catalysts until just above the point at which water freezes homogeneously. ${ }^{2}$

Common experience also shows that if a soluble substance is dissolved in water, both the melting and freezing temperatures are reduced. (Note that while the melting point is a well defined value, the freezing point is statistical, depending on the volume of water, the rate at which it is cooled, etc...) If both a soluble and insoluble substance are added, the soluble substance depresses the freezing point, but the insoluble substance will act to increase the characteristic freezing temperature of the solution.

The two most studied forms of heterogeneous freezing of water are the immersion mode, wherein the catalyzing substance is wholly immersed within the bulk water, and the deposition mode, in which an ice crystal forms on the surface of the catalyst directly from the vapor phase. If the catalyzing substance impinges upon the surface of the supercooled water, a third mode is possible, the so-called contact mode. Early work on the topic showed that aerosol particles which hit a supercooled droplet of water induced freezing at temperatures higher than if the same particles had been 
immersed within the droplet. ${ }^{3-5}$ More recent work has shown that the probability of a single aerosol particle initiating freezing upon colliding with a droplet of water at supercoolings of 15 to $25^{\circ} \mathrm{C}$ is only $10^{-3}$ or lower. ${ }^{6,7}$ However, those experiments also confirmed that for a single particle-droplet collision, contact freezing is more probable than is immersion freezing.

Why is freezing more likely when the catalyst impinges upon the air-water interface? Proposed mechanisms include subcritical ice embryos adsorbed to the surface of incoming particles, ${ }^{8}$ a momentary reduction in the free energy barrier between water and ice as a result of the heat of wetting, ${ }^{9}$ an intrinsic reduction in the free energy barrier at a three phase contact line, ${ }^{10-13}$ and the presence of small scale features at the contact line. ${ }^{14}$ (See Ladino Moreno et al. ${ }^{15}$ for a more comprehensive review of theories and studies of contact nucleation.) Knollenberg proposed yet another mechanism for contact nucleation involving soluble substances, having recognized that most of the salts present in the atmosphere are endothermic upon dissolution. ${ }^{16,17}$ Salt impinging upon a water surface induces cooling in the surrounding liquid as heat is absorbed as the bonds within the salt are broken and the resulting ions hydrated. If the water is cooled below the eutectic point for the water-salt system, freezing is possible with the solid salt as a substrate. Alternatively, water may be cooled below its homogeneous freezing limit, inducing freezing before the ions from the dissolving crystal have diffused into the region which has been supercooled to that point.

Most contact freezing experiments have been with insoluble substances, motivated in part by the supposition that a substance likely to catalyze freezing when fully immersed within bulk water might also be likely to initiate freezing in the contact mode. Early work showed that silver iodide, sand, and clay triggered freezing at a 
higher temperature in the contact mode than in the immersion mode. ${ }^{3}$ However, in the same article, the authors briefly mention that salt and sugar were also contact nuclei, at -11 and $-13.5^{\circ} \mathrm{C}$ respectively. No discussion was offered as to the mechanism of freezing by a soluble substance. (Note that $-11^{\circ} \mathrm{C}$ is well above the eutectic point for water and $\mathrm{NaCl}$.)

We have tested six soluble substances (KCl, KI, NaCl, NaI, NaOH, and KOH; chemicals were purchased from Alfa Aesar and Fisher Scientific and used as received) as contact nuclei, using a variation of the technique we developed for smaller particles of mineral dust and bacteria. ${ }^{6,18}$ In essence, the experiment is a cold stage with a temperature controlled vertical tube above it. Because we wanted to test larger particles (25 $\mu \mathrm{m}$ to a few hundred $\mu \mathrm{m}$ diameter), the system is oriented vertically such that the test particles fall onto the test droplets. The distance fallen is such that particles reach terminal velocity and equilibrate with the air temperature within the tube. More detail is given in the Experimental Methods section and the Supplementary Material.

In 5 we report the threshold temperature, $T_{0}$, as the lowest temperature at which collisions of our test compounds with a supercooled droplet produced no freezing events. Below $T_{0}$, all of the substances exhibited freezing. $T_{80}$ is the temperature at which freezing occurred in four out of five tests. The eutectic temperature $T_{\text {eutectic }}$, heat of dissolution $\Delta H_{\text {dissolution }}$, and density $\rho$, are all taken from values reported in literature.

$T_{0}$ clearly shows a dependence on composition, and a decrease in the temperature leads to an increase in the probability that freezing will occur. The majority of tests 
Table 5: Threshold freezing temperature $\left(T_{0}\right), 80 \%$ freezing temperature $\left(T_{80}\right)$, eutectic temperature $\left(T_{\text {eutectic }}\right)$, heat of dissolution $\left(\Delta H_{d}\right)$, and density $(\rho)$ of the alkali salts tested for contact freezing activity. The heats of dissolution and densities are taken from the CRC Handbook ${ }^{19}$ while the eutectics are taken from Solubilities. ${ }^{20}$

\begin{tabular}{lccccc}
\hline Substance & $T_{0}\left({ }^{\circ} \mathrm{C}\right)$ & $T_{80 \%}\left({ }^{\circ} \mathrm{C}\right)$ & $T_{\text {eutectic }}\left({ }^{\circ} \mathrm{C}\right)$ & $\Delta H_{d}(\mathrm{~kJ} / \mathrm{mol})$ & $\rho\left(\mathrm{g} / \mathrm{cm}^{3}\right)$ \\
\hline $\mathrm{NaI}$ & -7 & -13 & -31.5 & -7.53 & 3.67 \\
$\mathrm{KI}$ & -8 & -12 & -23.2 & 20.33 & 3.1 \\
$\mathrm{NaOH}$ & -11 & -15 & -28 & -44.51 & 2.13 \\
$\mathrm{KOH}$ & -11 & -15 & -62.8 & -57.61 & 2.12 \\
$\mathrm{NaCl}$ & -12 & -15 & -21.2 & -3.88 & 2.16 \\
$\mathrm{KCl}$ & -12 & -13 & -10.8 & 17.22 & 1.98 \\
\hline
\end{tabular}

are performed above the solute-water eutectic, with the exception of $\mathrm{KCl} . T_{0}$ for $\mathrm{KCl}$ is below the eutectic; the equilibrium state is solid salt plus ice. It is possible in this case that ice could form directly from the vapor phase on the falling salt crystal, triggering freezing of the test droplet upon contact. However, we consider it more likely that the crystal began to dissolve as it fell through the droplet's vapor field, following Ostwald's rule of stages, resulting in a metastable solution of dissolved ions.

In these experiments, the collision of the aerosol particle with the test droplet must have triggered freezing. The particles cannot act as catalysts in the bulk liquid at these supercoolings because they would simply reduce the freezing point upon dissolution. (As noted above, $\mathrm{KCl}$ is the exception to this.) It has been suggested that the sites which catalyze freezing in the immersion mode (so-called active sites) are also the sites which trigger contact freezing, though it is not known why these domains would be effective at higher temperatures when at the air-water interface than when in the bulk. ${ }^{7}$ In the experiments described here, the particles have no immersion mode active sites. Thus freezing must be initiated by the collision. As further confirmation of this, we melted some of the droplets, then cooled them back to the temperature of the original contact freezing test. None of them froze when 
subjected to this procedure, corroborating our assertion that the phase transition is nucleated by the particles' impact.

We rule out the presence of sites upon the surface of the falling particles which catalyze freezing before they begin to dissolve because droplets have already begun to deliquesce when they collide with the test droplet. Droplets are allowed to reach thermal and evaporative equilibrium before a freezing test begins; the vapor field around it will cause falling particles to take up water and begin to deliquesce, forming a brine layer. Cooper ${ }^{8}$ estimated that a monolayer of water will form on a solid surface as it falls through a vapor field in $10^{-4} \mathrm{~s}$; salt particles do begin to take up detectable amounts of water, even before deliquescence, so we are confident that the particles in our system have at least begun to deliquesce when they hit the droplet. (See the Supplementary Material for an estimation of the time required for particles to form a layer of brine upon the surface.) In the case of $\mathrm{NaI}, \mathrm{NaOH}$, and $\mathrm{KOH}$, the brine layer will be heated above the temperature of the ambient air due to exothermic dissolution and condensation. The condensation of water vapor and the associated release of latent heat will be partially offset in the case of the three endothermic salts. In any case, the particles which collide with the test droplet are not dry solids.

None of the mechanisms ${ }^{15,16}$ of contact freezing listed above are consistent with these experiments, with the possible exception of one proposed by Fukuta, discussed in further detail below. The mechanism cannot depend on the presence of a solid surface, ${ }^{8,10,11,14}$ as there is no solid surface upon which a pre-critical ice embryo could form. The local cooling hypothesis, proposed by Knollenberg ${ }^{16,17}$ is also discarded because $\mathrm{NaI}, \mathrm{KOH}$, and $\mathrm{NaOH}$ are exothermic upon dissolution. Water in the vicinity of the aerosol particle's impact is heated, not cooled. 
Eliminating most of the proposed contact freezing mechanisms and considering the fact that collisions of $10 \mu \mathrm{m}$ diameter particles of $\mathrm{NaCl}$ with test droplets did not cause freezing in experiments we conducted with our flow-through system ${ }^{18}$ leads us to the size of the particles as a possible cause of the freezing. (A more detailed explanation of the tests with $\mathrm{NaCl}$ in the flow-through system is given in the Supplementary Material.) Larger particles fall at higher speeds and thus create a more pronounced mechanical disturbance upon collision with the droplet. 13 is a plot of the area equivalent diameter, $D_{e q}$, of dry particles that fell directly onto the microscope slides we use as substrates for the test droplets.

$$
D_{e q}=\sqrt{\frac{4 A_{p}}{\pi}}
$$

where $A_{p}$ is the projected area of a given aerosol particle on the slide. (The mass of salt which collided with the droplets in each of the freezing tests is shown in the Supplementary Material. Those masses are determined by measuring the volume of the residue left after the water evaporates.) The majority of the particles which collided with test droplets had diameters between 50 and $150 \mu \mathrm{m}$. The distributions for $\mathrm{NaI}$ and KI peak at smaller diameters because they are denser, and smaller particles still have the inertia to overcome the counterflow. 13 shows that the variation in the size distributions among the compounds we tested is not dramatic which indicates that differences in the sizes of the particles is unlikely to explain the differences in the threshold freezing temperatures which we observe.

To further explore the difference in the freezing efficacy of the compounds, we plot in 14 the highest temperature at which freezing was observed, $\left(T_{0}-1^{\circ} \mathrm{C}\right)$, for each substance as a function of the density. It scales almost linearly. The most obvious 


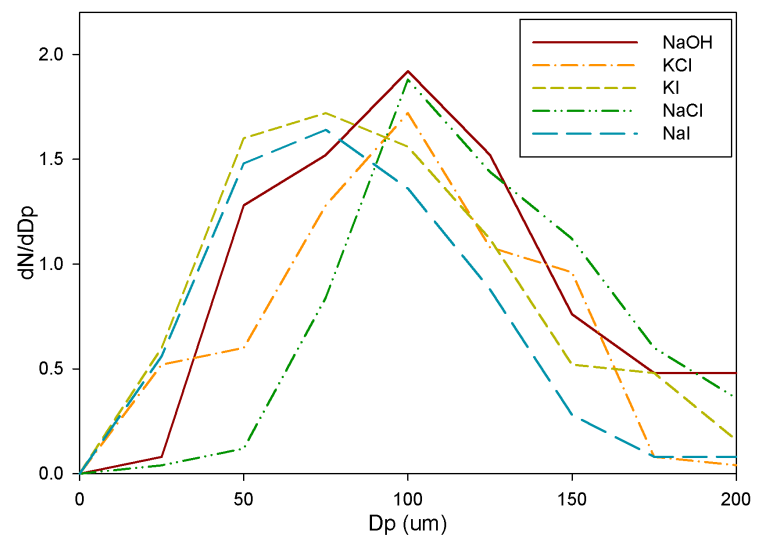

Figure 13: Area equivalent diameter of dry particles that fell through the system. From visual inspection, none of the particles had aspect ratios greater than 2. Due to the counterflow, less dense salts peaked at larger diameters. We were unable to obtain size distributions from $\mathrm{KOH}$ because the aerosol particles deliquesced.

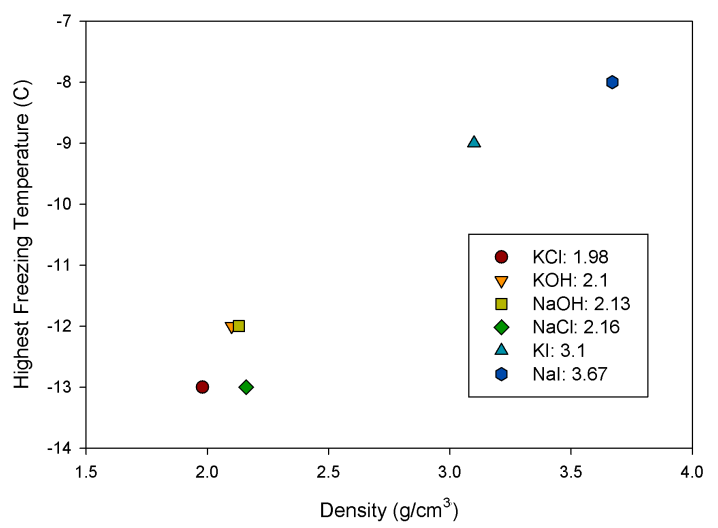

Figure 14: The highest temperature at which freezing was observed, $\left(T_{0}-1{ }^{\circ} \mathrm{C}\right)$, plotted as a function of the density for all the compounds tested. 
conclusion is that the fall speed is determining $T_{0}$, given that the sizes of the particles are similar, but the densities vary. The lack of correlation with the heat of dissolution leads us to believe chemistry is not playing a dominant role in the freezing process.
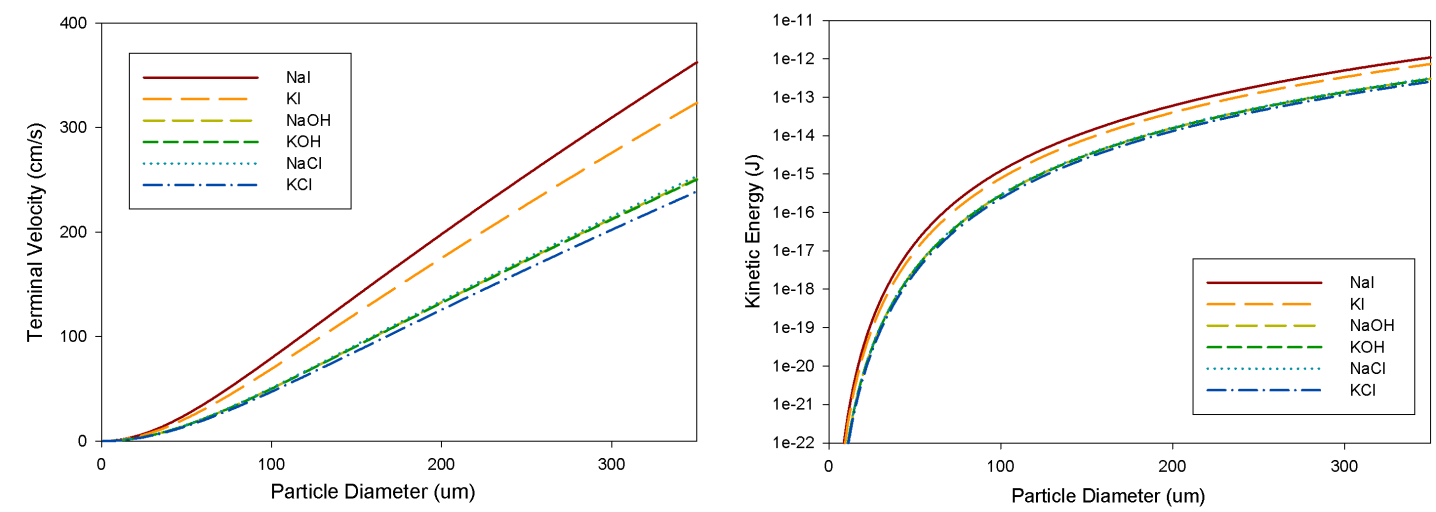

Figure 15: Left: Terminal velocity of spheres of the specified density as a function of the diameter. Terminal velocity is calculated numerically from expressions for terminal velocity as a function of the drag coefficient. ${ }^{21}$ The salt particles are nonspherical, so the actual velocity will be slightly below the values shown here. ${ }^{21}$ Right: The kinetic energy follows directly from the terminal velocity, proportional to $v_{T S^{2}}{ }^{2}$ and $D_{p}{ }^{3}$

The left panel of 15 shows calculated terminal velocities as a function of diameter and density. The velocities of the particles cover approximately a factor of 50, from the smallest, least dense particles, to the largest, most dense. For example, a 25 micron diameter particle of $\mathrm{KCl}$ has a terminal velocity of $4 \mathrm{~cm} / \mathrm{s}$ while a 200 micron diameter particle of $\mathrm{NaI}$ has a terminal velocity of $200 \mathrm{~cm} / \mathrm{s}$. At the time of collision, the particles are moving at or near terminal velocity. Recall however, that the particles are taking up water as they fall through the droplet's vapor field, so they are accelerating slightly. The calculated kinetic energy carried by particles of a given diameter and density is plotted in the right panel of 15. The natural energy scale for this problem is the magnitude of the Gibbs free energy barrier to nucleation, $\Delta G$, which Sanz et al. ${ }^{22}$ have estimated as $515 \mathrm{k}_{B} \mathrm{~T}$ or $1.84 \times 10^{-18} \mathrm{~J}$ for homogeneous nucleation at a 
supercooling of $14.5^{\circ} \mathrm{C}$. Nearly all particles with a diameter larger than $50 \mu \mathrm{m}$ carry this energy. If the energy of a particle-droplet collision were such that it somehow triggered freezing, we should see no dependence on the particles' composition.

However, our results do suggest that the collision can introduce energy to the metastable liquid in a way that promotes nucleation. Fukuta ${ }^{9}$ argued that perhaps a transient zone of increased free energy is responsible for the fact that contact mode freezing typically occurs at higher temperatures than does freezing in the immersion mode. As surfaces come very near liquid water, vapor molecules will adsorb to the solid. Upon being plunged into the bulk, these molecules must reorient to accommodate for hydrogen bonds with the liquid structure. The energy associated with that reorientation is the difference in the free energies of the adsorbed molecules and the bulk water, i.e. the heat of wetting. Fukuta proposed that the transient increase in free energy at the interface might temporarily lower the free energy barrier to nucleation in the adjacent layers. Hence the only requirement for an increased nucleation rate upon contact is the continual subduction of adsorbed vapor molecules into the bulk.

In the context of Classical Nucleation Theory, the Gibbs free energy difference upon creation of an ice embryo upon a substrate (e.g. an aerosol particle) is usually written $\operatorname{as}^{24}$

$$
\Delta G=-V_{i} \Delta \mu+A_{i, l} \sigma_{i, l}+A_{i, s} \sigma_{i, s}-A_{i, s} \sigma_{l, s}
$$

where $V_{i}$ is the volume of the ice nucleus, $\Delta \mu$ is the free energy difference per volume between ice and liquid, $A_{i, l} \sigma_{i, l}$ is the free energy cost of the ice-liquid interface, and $A_{i, s} \sigma_{i, s}-A_{i, s} \sigma_{l, s}$ is the change in free energy upon replacing an area of the substrate in contact with the liquid with one in contact with the ice embryo. Fukuta noted that the 
final term in 2 is where the transient increase in the free energy due to wetting would manifest itself, as $\sigma_{l, s}$ is increased, lowering $\Delta G$ in total. In the experiments described here, the first two terms in 2 remain, but the remaining ones are questionable since the particles start to deliquesce before they make contact with the test droplet. However, it is clear that some transient effect, which is a consequence of the collision (e.g. the pressure wave which radiates out from the site of the impact), results in a lower energy barrier and higher nucleation rate.

Though we can only speculate at this time as to the mechanism of contact freezing in our experiments, we can place limits on the time scale in which the freezing takes place. We start by assuming that the nucleation event occurs in the "most likely" conditions, when the water droplet is coldest and before any ions diffuse into the region in which the critical nucleus forms. We see freezing for both endothermic and exothermic heats of dissolution, so we rule out the possibility that dissolution forms a locally cold region which facilitates formation of a critical embryo. The critical embryo must form before any heat from the exothermic compounds propagates into the pure water. We also rule out the possibility that the critical embryo forms on the salt surface itself, as in the case of deposition nucleation, because of the brine layer which forms as the particles fall through the droplet's vapor field.

The time scale for diffusive processes can be estimated as

$$
\tau=\frac{L^{2}}{D}
$$

where $L$ is a characteristic length and $D$ is the diffusion coefficient. The diffusion coefficient for ions in water ${ }^{25}$ and the thermal diffusivity of water ${ }^{19}$ are $D_{\text {ions }}=$ $2 \times 10^{-5} \mathrm{~cm}^{2} / \mathrm{s}$ and $D_{\text {thermal }}=0.0014 \mathrm{~cm}^{2} / \mathrm{s}$ respectively. The other time scale 
to consider is the time required for a pressure wave to travel the distance $L$. The pressure, or mechanical, timescale is then simply $\tau=\frac{L}{v_{\text {sound }}}$ where we have taken $v_{\text {sound }}=1400 \mathrm{~m} / \mathrm{s}$. (The variation in the speed of sound with temperature plays a negligible role here.)

16 is a plot of the three timescales as a function of distance from an impact of an aerosol particle with a test droplet. The plot shows that ions diffuse into the droplet slowly leaving diffusion of heat and the time for the pressure wave to propagate as limits for a nucleation event. Since the freezing event is triggered by the impact of the particle with the droplet, and the fact that a collision has occurred is carried at the speed of sound, the lower bound is set by the time for the pressure wave to reach a given distance away from the impact. Heat released as exothermic compounds dissolve raises the temperature of the water, decreasing the nucleation rate, setting the upper bound for the timescale in which the nucleation even could be triggered. The lower plot in 16 shows the timescales if the freezing event takes place within 100 $\mathrm{nm}$ of the impact. The size of the critical nucleus at a supercooling of $14.5^{\circ} \mathrm{C}$ is $\sim 6$ nm. ${ }^{22}$ Close to the point of impact, nucleation must be quite rapid, on the order of $10^{-8}$ seconds.

Much of the research in contact freezing has been motivated by its possible relevance for ice initiation in Earth's atmosphere. The results presented here will not be directly relevant for that since there are very few salt crystals with a size of hundreds of microns at elevations relevant for ice formation. However, the fact that contact nuclei need not be effective as immersion mode nuclei should be relevant in the search for a more comprehensive description of freezing by atmospheric aerosol. More generally, our results suggest that the kinetic energy from a mechanical disturbance can contribute 

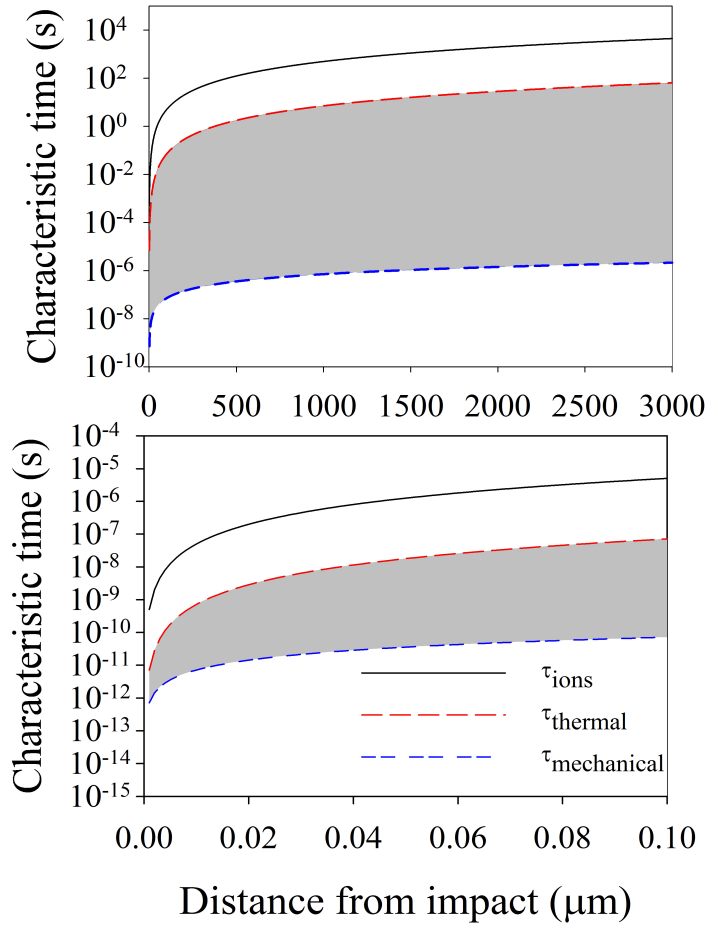

Figure 16: Upper panel: The three characteristic timescales as a function of the distance from an impact of an aerosol particle with a test droplet. The test droplets are $\approx 3 \mathrm{~mm}$ (i.e. $3000 \mu \mathrm{m})$ in diameter. The shaded region shows the bounds for the timescale for nucleation. Lower panel: If the nucleation event takes place within 100 $\mathrm{nm}$ of the point of impact, the time scale for nucleation is on the order of $10^{-8} \mathrm{~s}$. 
to a reduction in the free energy barrier to nucleation, enhancing the probability of a phase transition.

In summary, we have shown that collisions of simple ionic substances with moderately supercooled water will trigger freezing. This effect must depend upon the collision itself, as the substances we have used as freezing catalysts would depress the freezing point upon dissolution into the bulk. In other words, we have shown that contact freezing nuclei need not be effective as immersion mode nuclei since none of the catalysts described here will act as freezing nuclei in the immersion mode. These results are consistent with only one of the many mechanisms proposed to explain why contact freezing is typically more likely than freezing in the immersion mode. Further, because we can estimate time scales for competing processes in the systems we have tested, we can place stringent limits upon the time scale in which contact freezing must be initiated.

\section{Experimental Methods}

Our technique for quantitative measurement of contact freezing of water initiated by the impact of aerosol particles composed of simple ionic substances is based on the same principle as our previous measurements of contact freezing by dusts and bacteria. ${ }^{6}$ Measurement of contact freezing differs from the measurement of other modes of heterogeneous nucleation in that the surface of a supercooled droplet of water must come into contact with an aerosol particle and the subsequent freezing event detected. For quantitative assessment, the number of aerosol-droplet interactions before freezing must be known. 
Our basic approach, shown schematically in 17, is to allow aerosol particles to settle at terminal velocity onto a supercooled droplet. We do this for two reasons. The first is so the speed of impact is known. The second is so the vapor field around the droplet is steady until the aerosol particles pass through it. This is unique from other designs, where, for example, the particles are introduced to the air upstream of the droplet, and carried to it by an airflow. 3,18
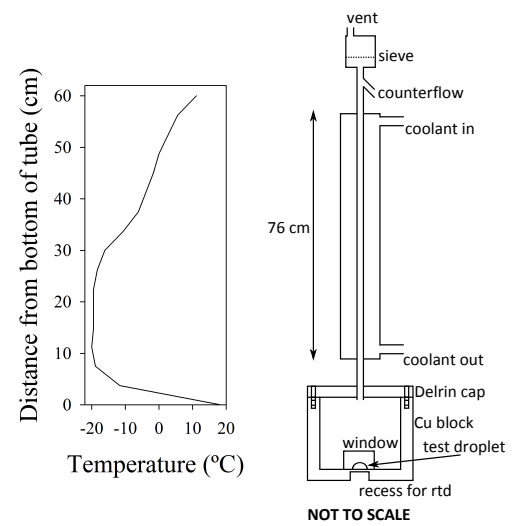

Figure 17: Schematic cross section of the vertically oriented contact freezing system and the temperature profile within the drop tube. The high temperatures near the bottom of the fall tube are an artifact of having the copper chamber open while measuring the temperature profile. Note that the schematic is not to scale.

The basic elements of the technique are a particle hopper, a fall tube, and a cold stage. Particles in the hopper are roughly size selected using a brass mesh of known size. Those smaller than the mesh size fall into the tube. A counter flow is used to reject smaller particles $\left(\mathrm{D}_{p}<\sim 50 \mu \mathrm{m}\right)$. Note that because particles are rejected in the counterflow based on the aerodynamic diameter, which depends on the density of the particles, the size rejected depends on the chemical composition of the particles.

Larger particles (not rejected by the counterflow) fall through the $\frac{1}{4}$ inch o.d. tube onto the droplet. The section of the tube above the droplet is jacketed by a hollow 
PVC pipe filled with coolant. The coolant is kept at a constant temperature with a circulating liquid chiller (Julabo, CF40) to reduce the difference between the aerosol and droplet temperature. The temperature profile is shown in 17.

The test droplets sit directly under the drop tube in a milled copper block, which serves to stabilize the temperature. The block is thermostatted with a Peltier element (Ferrotec) driven with an Accuthermo temperature controller (FTC 100). The temperature of the droplet is inferred from an rtd which sits in a recess directly underneath it. The air temperature is also monitored with a type $\mathrm{K}$ thermocouple. The temperature readings of the rtd and thermocouple in the sample chamber were calibrated against the melting point of a droplet of pure water.

The test droplets are $5 \mu \mathrm{l}$ and sit on a silanized glass slide (Hampton Scientific). Freezing events are detected by focusing a HeNe laser through the droplet onto a photodiode. Upon freezing, the opacity of the droplet changes dramatically, resulting in a corresponding decrease in signal at the photodiode. Freezing is also confirmed visually by opening the chamber after a freezing event is registered by the photodiode.

Because we have used soluble substances, the size distributions of the particles which fall onto the droplets are determined in separate experiments in which a test droplet is not on the cold stage. The aerosol particles fall onto one of the glass slides, which is then removed from the cold stage and examined with an optical microscope. The cross sectional area of the particles on the slide is determined from an analysis of digital images, using ImageJ. The diameters we report are the area equivalent diameters, derived from the cross sectional area using 1 . We were able to derive distributions for five of the six substances used. We were unable to obtain reliable distributions for 
$\mathrm{KOH}$ because the particles deliquesced even in the low relative humidity of the lab.

We cannot derive size distributions of the particles which actually fall onto the test droplets because they dissolve. In those cases, we derive the mass of salt which impacted the droplet by removing it from the cold stage, allowing it to evaporate, and then examining the residue of salt left behind. The area equivalent diameter of the residue is derived in the same way as outlined above. The approximate thickness of the deposit is obtained by turning the slide 90 degrees and imaging the deposits again. Further details of the experiment and sample preparation are given in the Supplementary Material.

\section{Acknowledgement}

Funding from the National Science Foundation (AGS-1028998) is gratefully acknowledged. We also appreciate fruitful discussions with Fan Yang, Raymond Shaw, Dennis Niedermeier, Alex Kostinski, and Claudio Mazzoleni, all of whom helped us to clarify several ideas in the paper. A special thanks goes to Parker Schimler for help in designing the particle sieve.

\section{Supporting Information Available}

Further details of the sample preparation and other details of the drop tube experiment, experiments with $\mathrm{NaCl}$ conducted in the flow-through system, and the timescale for deliquescence are given in the Supplementary Material. This material is available 
free of charge via the Internet at http://pubs.acs.org/.

\section{Notes and References}

(1) Popovitz-Biro, R.; Wang, J. L.; Majewski, J.; Shavit, E.; Leiserowitz, L.; Lahav, M. Induced freezing of supercooled water into ice by self-assembled crystalline monolayers of amphiphilic alcohols at the air-water interface. J. Am. Chem. Soc. 1994, 116, 1179-1191.

(2) Hoose, C.; Möhler, O. Heterogeneous ice nucleation on atmospheric aerosols: A review of results from laboratory experiments. Atmos. Chem. Phys. 2012, 12, $9817-9854$.

(3) Gokhale, N.; Spengler, J. Freezing of freely suspended, supercooled water drops by contact nucleation. J. Appl. Meteorol. 1972, 11, 157-160.

(4) Pitter, R.; Pruppacher, H. A wind tunnel investigation of freezing of small water drops falling at terminal velocity in air. Q. J. Roy. Meteorol. Soc. 1973, 99, 540550.

(5) Sax, R.; Goldsmith, P. Nucleation of water drops by Brownian contact with AgI and other aerosols. Q. J. Roy. Meteorol. Soc. 1972, 98, 60-72.

(6) Niehaus, J.; Becker, J. G.; Kostinski, A.; Cantrell, W. Laboratory Measurements of Contact Freezing by Dust and Bacteria at Temperatures of Mixed-Phase Clouds. J. Atmos. Sci. 2014, 71, 3659-3667.

(7) Hoffmann, N.; Duft, D.; Kiselev, A.; Leisner, T. Contact freezing efficiency of mineral dust aerosols studied in an electrodynamic balance: quantitative size 
and temperature dependence for illite particles. Faraday Discuss. 2013, 165, $383-390$.

(8) Cooper, W. A possible mechanism for contact nucleation. J. Atmos. Sci. 1974, 31, 1832-1837.

(9) Fukuta, N. A study of the mechanism of contact nucleation. J. Atmos. Sci. 1975, 32, 1597-1603.

(10) Djikaev, Y.; Ruckenstein, E. Thermodynamics of heterogeneous crystal nucleation in contact and immersion modes. J. Phys. Chem. A 2008, 112, 1167711687.

(11) Sear, R. P. Nucleation at contact lines where fluid-fluid interfaces meet solid surfaces. J. Physics-Condensed Matt. 2007, 19, 466106, WOS:000250689100008.

(12) Shaw, R.; Durant, A.; Mi, Y. Heterogeneous surface crystallization observed in undercooled water. J. Phys. Chem. B 2005, 109, 9865-9868.

(13) Gurganus, C.; Kostinski, A. B.; Shaw, R. A. Fast Imaging of Freezing Drops: No Preference for Nucleation at the Contact Line. J. Phys. Chem. Lett. 2011, 2, 1449-1454, WOS:000291781700019.

(14) Gurganus, C.; Charnawskas, J.; Kostinski, A.; Shaw, R. Nucleation at the Contact Line Observed on Nanotextured Surfaces. Phys. Rev. Lett. 2014, 113, 235701.

(15) Ladino Moreno, L. A.; Stetzer, O.; Lohmann, U. Contact freezing: A review of experimental studies. Atmos. Chem. Phys. 2013, 13, 9745-9769.

(16) Knollenberg, R. G. The local cooling ice nucleation model. J. Atmos. Sci. 1969, 26, 125-129. 
(17) Knollenberg, R. G. A laboratory Study of the local cooling resulting from the dissolution of soluble ice nuclei having endothermic heats of solution. J. Atmos. Sci. 1969, 26, 115-124.

(18) Niehaus, J.; Bunker, K.; China, S.; Kostinski, A.; Mazzoleni, C.; Cantrell, W. A technique to measure ice nuclei in the contact mode. J. Atmos. Ocean. Technol. 2013, 71, 3659-3667.

(19) Weast, R. C., Ed. CRC Handbook of Chemistry and Physics, 58th ed.; CRC Press: Cleveland, 1977.

(20) Linke, W. Solubilities Inorganic and metal-organic compounds, 4th ed.; American Chemical Society: Washington, D.C., 1965; Vol. II.

(21) Hinds, W. C. Aerosol Technology; John Wiley \& Sons: New York, 1982.

(22) Sanz, E.; Vega, C.; Espinosa, J. R.; Caballero-Bernal, R.; Abascal, J. L. F.; Valeriani, C. Homogeneous ice nucleation at moderate supercooling from molecular simulation. J. Am. Chem. Soc. 2013, 135, 15008-15017.

(23) Lamb, D.; Verlinde, J. Physics and Chemistry of Clouds; Cambridge University Press: Cambridge, 2011.

(24) Ref. 23, Chpt. 7.

(25) Cussler, E. Diffusion: Mass Transfer in Fluid Systems, 2nd ed.; Cambridge University Press: New York, 1997. 


\section{Chapter 6}

\section{Future Work}

There were a number of exploratory experiments performed in the Atmospheric Science Lab at Fisher B021 that, although not complete, may serve to guide future generations. First we will explore those with the least structure, then move on to those with more.

\subsection{Terminal Velocity}

The experiment described in Chapter 6 took advantage of the different densities of salt as a proxy for terminal velocity. Denser particles of the same size will reach a higher settling velocity. The same effect could be achieved by changing the density of air in the system. The copper stage at the bottom has a port to the side that can be put under vacuum, and the air evacuated. The same effect of varying fall speed can be achieved with the exact same substance, removing any variations in preparation. Depending on the results, this could also lend credibility to the idea that chemistry is not determining the ice nucleation. 


\subsection{Biomass Burning}

The effect of wildfires on ice nuclei in the atmosphere has been of interest to the scientific community for some time. Some efforts have been taken to characterize soot in the immersion and deposition modes [1] [8] [3] [9] [4], and find carbon to be

a pretty poor nucleator. However, thus far no efforts have been made to quantify the contact mode.

The difficulty with soot is that depending on the temperature of the burn and composition of the source, the particles end up with different morphologies and organic coatings. The composition and morphology of soot particles in the atmosphere varies widely based on source material, burn conditions, interaction with chemical species, and photo-oxidation. Time spent in the atmosphere tends to compact the soot particles, making them more spherical, while they accrue a liquid shell of secondary organic aerosol.

The implications of these processes on ice nucleating ability is unclear. Experiments [1] indicate that liquid coatings increase IN activity. However, to understand all these processes is a very expensive (both in time and money) endeavor, and our initial experiments are an attempt to quantify the range of IN activity.

\subsubsection{Biomass Generation for the CINC}

With the help of Parker Schimler, we developed two methods of generating smoke and soot particles for characterization with the CINC described in Chapter 4. The first is a slightly modified wood smoker. The exhaust was drilled for an exit port, where 
smoke can be drawn off under vacuum. It is important to note that the smoke plume will be considerably hotter than room air, and efforts should be taken to ensure that it is cooled appropriately by the time it reaches the cold stage.

The second method is the use of a butane torch to turn biomass samples into ash. The ash is then put into the a wrist-action shaker (Burrell Scientific LLC) and agitated.

Samples of Red Oak, White Oak, Douglas Fir, Spruce, Birch, and Pine were collected locally in the Keweenaw region, Michigan. They were then turned into aerosol by one of the methods listed above. It was soon discovered that unless the samples are dried, they decay despite being in sealed plastic bags. The samples then must be labeled by time elapsed since collection.

Generating a fire similar to a forest fire is a difficult endeavor. Instead of trying to recreate the burn conditions, we will generate soot from different samples and look for any obvious characterization differences. Should there appear to be different nucleating efficiencies, we can then investigate the sample and burn conditions more rigorously. Surveying soot for contact mode has not yet been attempted, and the data can obtained can be used as a bounds for IN efficiency until it is better understood.

\subsubsection{Preliminary Results}

The same procedure described in Articles 1 and 2 has been used to characterize ash from the butane torch method. Results indicate some sample variation. Ashes from Douglas fir have an efficiency (defined in Chapter 4) of $7.6 \times 10^{-5}$ at $-20 \mathrm{C}$ while Red Oak shows an efficiency of $1.1 \times 10^{-3}$. The data is suggestive, but again without rigorous control on the burn conditions the most we can say is that these efficiencies are similar to those of mineral dust from Chapter 5 . 
Future studies will look into the variability of a single species as it ages, and characterize the efficacy of the dust plumes instead of just the residual aerosol. By using the Fourier Transfer Infrared Spectrometer available, some information about burn variability and organic content can be recovered. Although, that is likely a dissertation in itself. 


\section{References}

[1] Sarah D Brooks, Katie Suter, and Laura Olivarez. Effects of chemical aging on the ice nucleation activity of soot and polycyclic aromatic hydrocarbon aerosols. The Journal of Physical Chemistry A, 118(43):10036-10047, 2014.

[2] W. Cooper. A possible mechanism for contact nucleation. J. Atmos. Sci., 31: 1832-1837, 1974.

[3] Paul J DeMott. An exploratory study of ice nucleation by soot aerosols. Journal of Applied Meteorology, 29(10):1072-1079, 1990.

[4] K Diehl and SK Mitra. A laboratory study of the effects of a kerosene-burner exhaust on ice nucleation and the evaporation rate of ice crystals. Atmospheric Environment, 32(18):3145-3151, 1998.

[5] YS Djikaev and E Ruckenstein. Thermodynamics of heterogeneous crystal nucleation in contact and immersion modes. The Journal of Physical Chemistry A, 112(46):11677-11687, 2008.

[6] Aaron N. Fletcher. High-temperature contact nucleation of supercooled water by organic chemicals. J. Appl. Meteorol., 11(6):988-993, September 1972. ISSN 0021-8952. doi: 10.1175/1520-0450(1972)011〈0988:HTCNOS〉2.0.CO;2.

[7] N. H. Fletcher. Size effect in heterogeneous nucleation. The Journal of Chemical Physics, 29(3), 1958. 
[8] Adam P Fornea, Sarah D Brooks, Jeffrey B Dooley, and Auromeet Saha. Heterogeneous freezing of ice on atmospheric aerosols containing ash, soot, and soil. Journal of Geophysical Research: Atmospheres (1984-2012), 114(D13), 2009.

[9] Beth Friedman, Gourihar Kulkarni, Josef Beránek, Alla Zelenyuk, Joel A Thornton, and Daniel J Cziczo. Ice nucleation and droplet formation by bare and coated soot particles. Journal of Geophysical Research: Atmospheres (1984-2012), 116 (D17), 2011.

[10] N. Fukuta. A study of the mechanism of contact nucleation. J. Atmos. Sci., 32: 1597-1603, 1975.

[11] N. Gokhale and J. Goold, Jr. Droplet freezing by surface nucleation. J. Appl. Meteorol., 7:870-874, 1968.

[12] N. Gokhale and J. Spengler. Freezing of freely suspended, supercooled water drops by contact nucleation. J. Appl. Meteorol., 11:157-160, 1972.

[13] Peter V Hobbs. Ice physics. Oxford: Clarendon Press, 1974, 1, 1974.

[14] N. Hoffmann, A. Kiselev, D. Rzesanke, D. Duft, and T. Leisner. Experimental quantification of contact freezing in an electrodynamic balance. Atmos. Meas. Tech., 6(9):2373-2382, September 2013. ISSN 1867-8548. doi: 10.5194/amt-6-2373-2013.

[15] C. Hoose and O. Möhler. Heterogeneous ice nucleation on atmospheric aerosols: a review of results from laboratory experiments. Atmospheric Chemistry and Physics, 12(20):9817-9854, 2012. doi: 10.5194/acp-12-9817-2012. URL http: //www . atmos-chem-phys.net/12/9817/2012/.

[16] Hugh Morrison, Matthew D Shupe, James O Pinto, and Judith A Curry. Possible roles of ice nucleation mode and ice nuclei depletion in the extended lifetime of arctic mixed-phase clouds. Geophysical research letters, 32(18), 2005. 
[17] R. Pitter and H. Pruppacher. A wind tunnel investigation of freezing of small water drops falling at terminal velocity in air. Q. J. Roy. Meteorol. Soc., 99: 540-550, 1973.

[18] Hans R Pruppacher, James D Klett, and Pao K Wang. Microphysics of clouds and precipitation. Taylor \& Francis, 1998.

[19] R. Sax and P. Goldsmith. Nucleation of water drops by brownian contact with AgI and other aerosols. Q. J. Roy. Meteorol. Soc., 98:60-72, 1972.

[20] R. Shaw, A. Durant, and Y. Mi. Heterogeneous surface crystallization observed in undercooled water. J. Phys. Chem. B, 109:9865-9868, 2005.

[21] C. D. Westbrook and A. J. Illingworth. The formation of ice in a long-lived supercooled layer cloud. Quarterly Journal of the Royal Meteorological Society, 139(677):2209-2221, 2013. ISSN 1477-870X. doi: 10.1002/qj.2096. URL http: //dx.doi.org/10.1002/qj.2096. 